\title{
Intergenerational Occupational Mobility Among Men in Iran During 1996-2016
}

\author{
\begin{tabular}{l|l} 
Mohammad Hoseini ${ }^{1} \quad$ mo.hoseini@imps.ac.ir
\end{tabular}
}

\begin{abstract}
This paper documents the changes in intergenerational occupational mobility among men in Iran for the last two decades. To measure intergenerational mobility, the Altham distance between the job transition matrices has been used for during the period in question. The results suggest that for the period (1996-2011), occupational mobility declined; this downward trend is steeper in 2006-2011, and it has leveled off until 2016. One of the factors that explains this decrease in occupational mobility is the flat supply of public sector jobs. In the period in question, while active population increases by more than 10 million, the public sector jobs rise by less than 1 million, bringing about a higher level of competition for obtaining those jobs. The analysis shows that following this phenomenon, the chance for obtaining public sector job has increased greatly for those whose father had a public sector job. In addition, jobless growth and higher education boom are two potential reasons for the sharper reduction in mobility during 2005-2011.
\end{abstract}

Keywords: Social Mobility, Intergenerational Mobility, Inequality, Jobless Growth, Higher Education, Public Sector Employment.

JEL Classification: J45, D63, J62. 


\section{تحرك شغلى بين

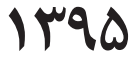

mo.hoseini@imps.ac.ir

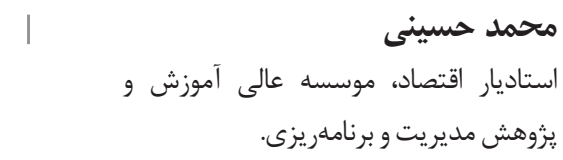

קذيرش:

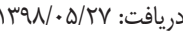

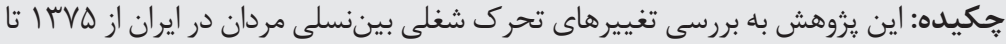

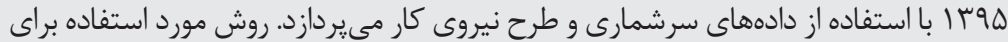

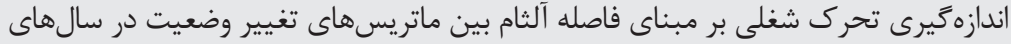

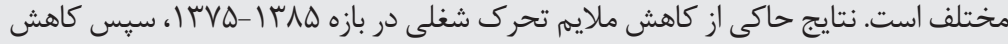

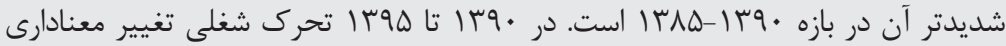

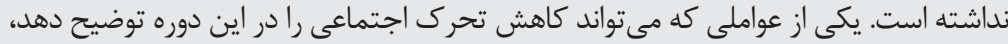

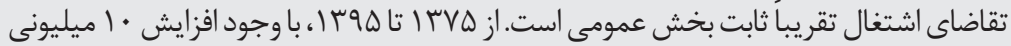
جمعيت فعال، مشاغل بخش عمومى كمتر از 1 ميليون افزايش يافته است و دادهّها نشان

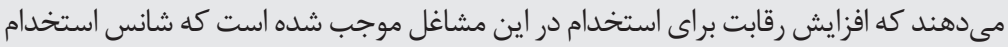

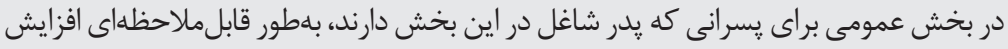

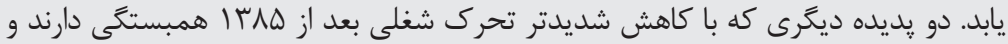

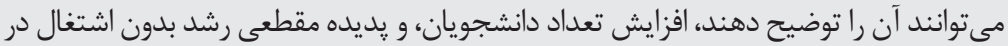
كشور هستند.

كليدوازهها: تحرى اجتماعى، تحرى بيننسلى، نابرابرى، رشد بدون اشتغال، تحصيلات

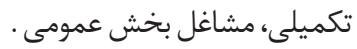
طبقهبندى J45, D63, J62 :JEL. 


\section{مقلم}

تحرك بيننسلى به معناى احتمال موفقيت يك فرد بر مبناى وضعيت والدينش، يك شاخص

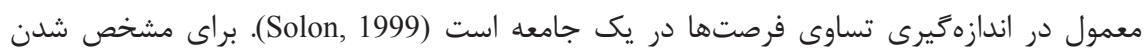

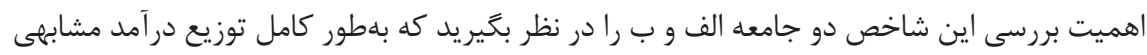

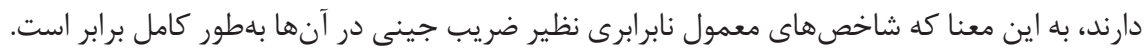

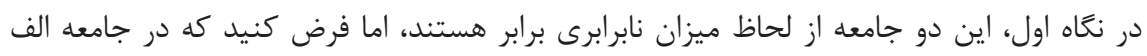

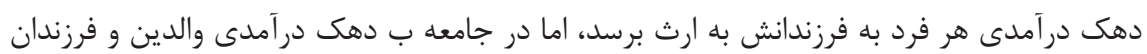
بلهطور كامل مستقل از هم باشند. در اين حالت، اگر كسى در جامعه الف در قشر فقير جامعه بهدنيا

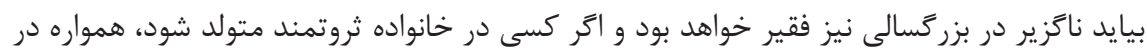

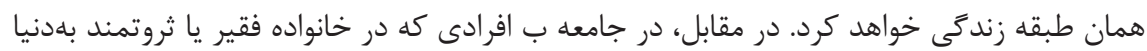

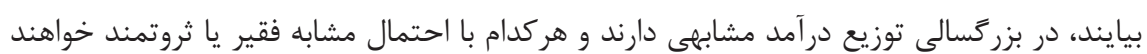

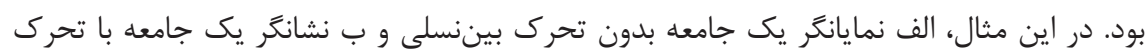

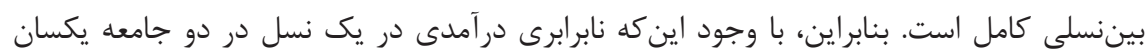

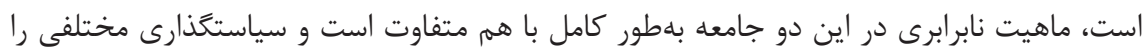
طلب مى كند. در ايران، شاخصهاى نابرابرى از ديرباز وجود داشته، اما شاخص تحرك اجتماعى در سطح كل

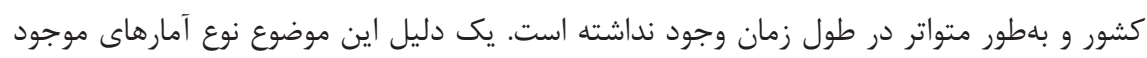

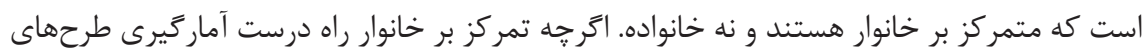
ملّى براى شاخصهاى كلان بازار كار مانند نرخ مشاركت و نرخ بيكارى است، اما در زمينه تحرك

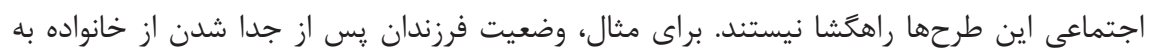

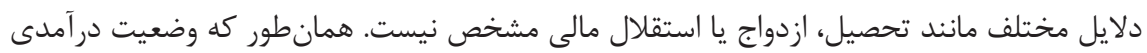

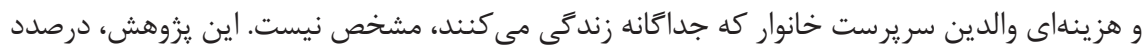

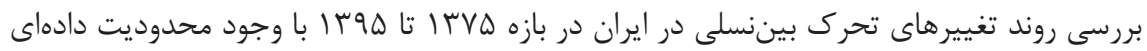
موجود و با تمركز بر تحرك شغلى و يدر-يسرهاى همخانه است.

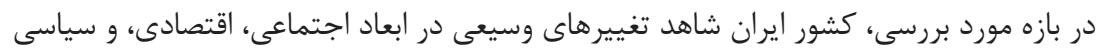

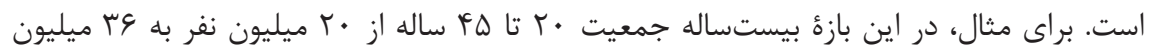

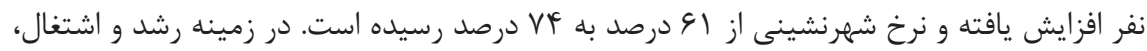




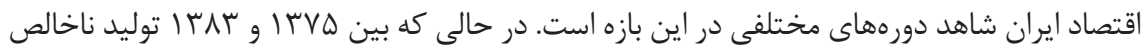

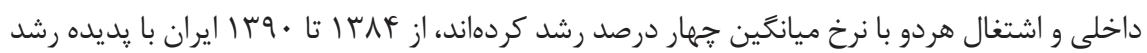

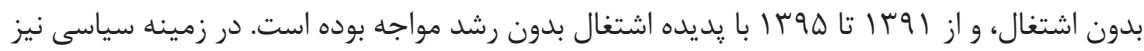
ايران در اين بازه بيستساله دولتهايى از طيفهاى مختلف سياسى را تجربه كرده است. با استفاده از دادههاى سرشمارى و طرح نيروى كار، تخمينهاى انجامَرفته نشان مى بدهند كه

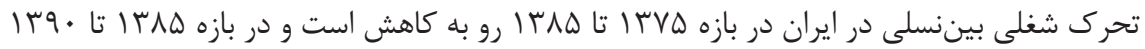

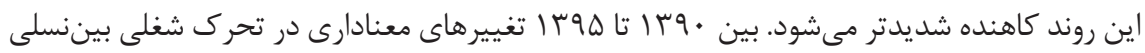

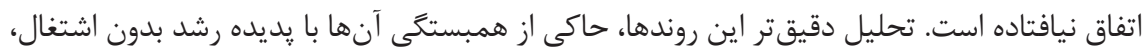

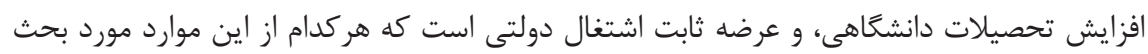
و بررسى قرار مى گيرد. البته، بررسىهاى صورتگرفته در اين يزوهش تنها بر مبناى همبستخى

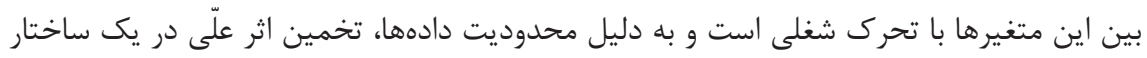

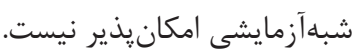

\section{مبانى نظرى يزوهش}

در زمينه تحرك بينسلى در كشورهاى توسعهيافته، ادبيات مفصلى وجود دارد كه در سولون

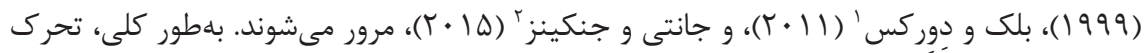
اجتماعى موضوعى حندبُعدى است و مىتواند از زاويههاى مختلفى مانند در آمد و شغل اندازهخيرى

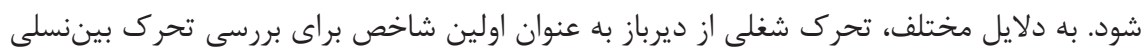

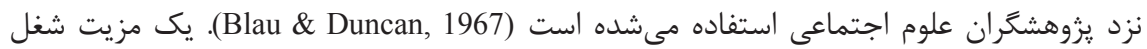
نسبت به درآمد براى اندازهيرى تحرى بيننسلى، كمتر بودن خطاى اندازهگيرى آن است. علاوه

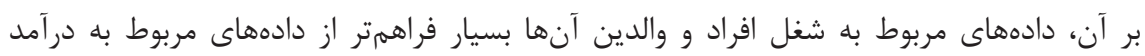

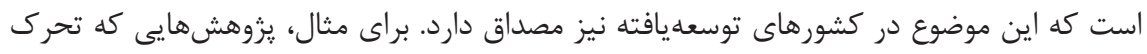

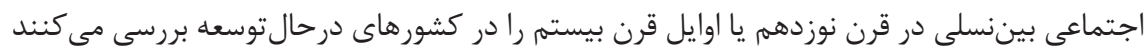

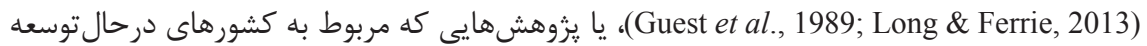
هستند (Reddy, 2015)، بر تحرك شغلى متمركز هستند. 


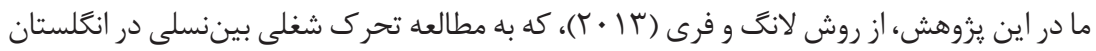

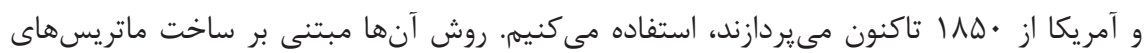
تغيير وضعيت براى زمانها و مكانهاى مختلف است، بهطورى كه سطرها و ستونهاى ماتريسها بلهترتيب متناظر با رده شغلى يدرها و وسرهاست. براى مثال، در ماتريس برابر تعداد يسرهايى است با شغل ز كه يدرشان داراى شغل i بودهاند. در حالت تحرك كامل، تمام

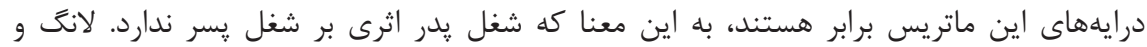

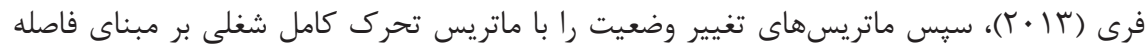

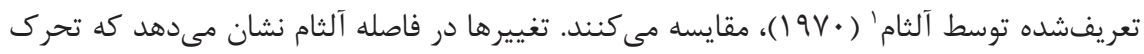

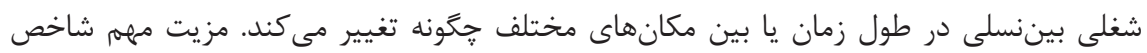

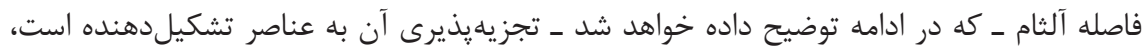

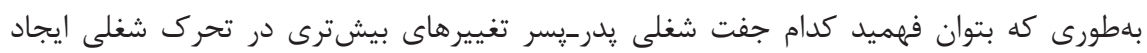

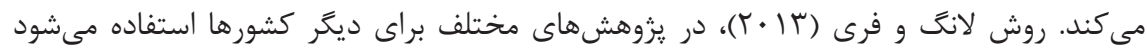

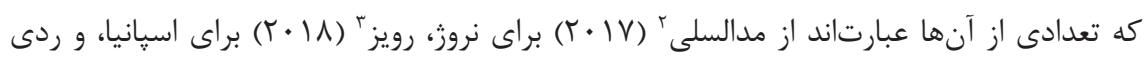

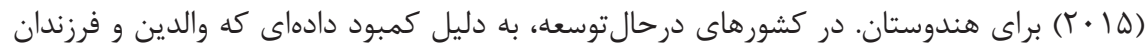

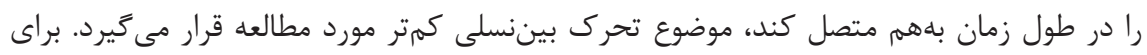

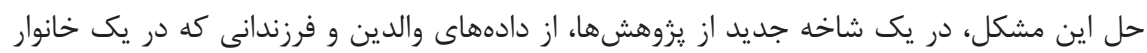

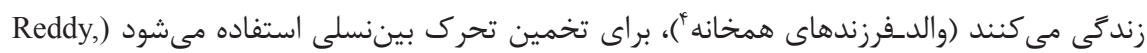

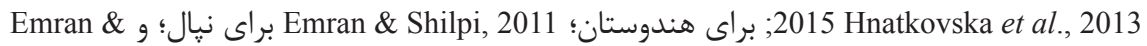
براى جين). با وجود اين كه در اين روش تخمين تحرك بين Sun, 2015

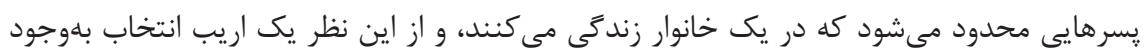

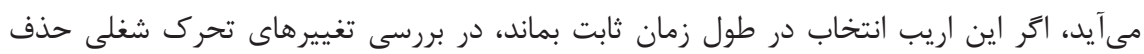

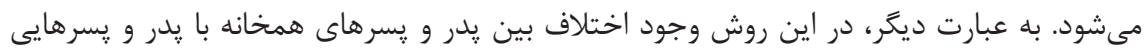

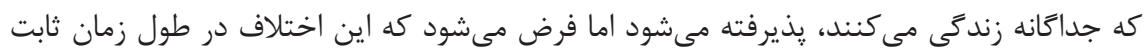

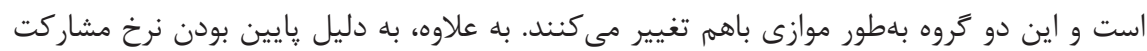

1. Altham

2. Modalsli

3. Ruiz

4. Co-Resident 
زنان در كشورهاى درحالتوسعه ـ كه در ايران هم مصداق دارد ـ تمامى يزوهشهاى اشارهشده در بالا فقط بر مردان شاغل تمركز دارند.

\section{روششناسى يثوهش}

با توجه به اين كه شغل متغيرى گسسته است، روش معمول براى اندازهيرى تحرك شغلى استفاده از جدول تغيير وضعيت است (Xie \& Killewald, 2013). براى مثال، فرض كنيد P دو ماتريس جريان شغلى باشند، بهطورى كه هر سطر نشاندهنده رده شغلى

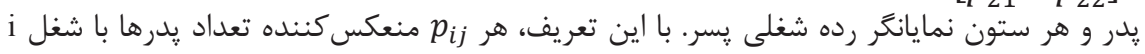

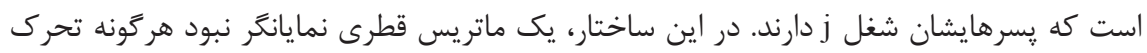

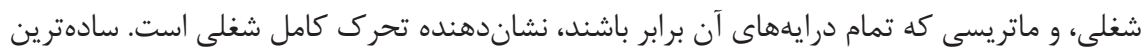

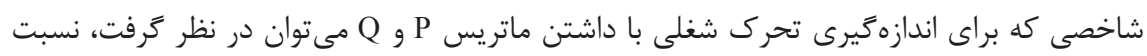
جمع درايههاى غيرقطرى آنها به جمع كل درايههاست:

\$. $\quad m_{P}=\frac{p_{12}+p_{21}}{p_{11}+p_{12}+p_{21}+p_{22}}, m_{Q}=\frac{q_{12}+q_{21}}{q_{11}+q_{12}+q_{21}+q_{22}}$

با اين تعريف، اما شاخص بالا يك ضعف بزرى دارد و آن متمايز نكردن تغييرهاى ساختارى اقتصاد با تغييرهاى

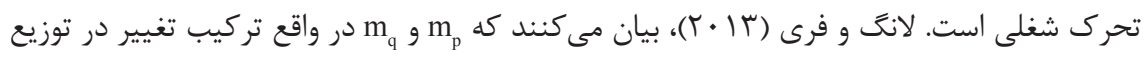

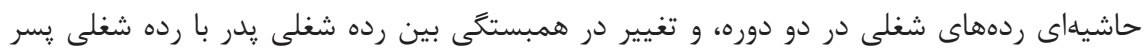

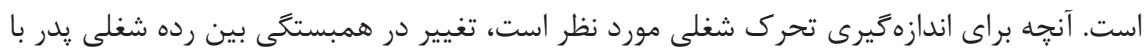
يسر است و نه تغيير در توزيع حاشيهاى ردههاى شغلى. براى مثال، اگر توزيع ردههاى شغلى به دليل

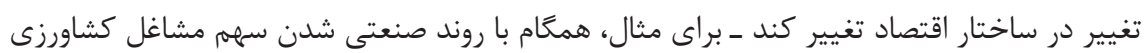

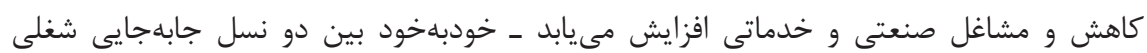
مشاهده مىشود كه به دليل تغيير در ساختار اقتصاد است نه تغيير در همبستخى رده شغلى يدر با پِر. به عبارت ديكر، تغييرهاى ساختارى اقتصادى باعث افزايش درايههاى غيرقطرى در ماتريس

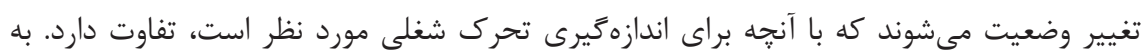
اين دليل براى اندازهيرى تحرى شغلى، مستقل از تغييرهاى ساختارى اقتصاد كه باعث تغيير 
توزيع فعاليتها مىشوند، در يك ماتريس جابهجايى بXY از نسبت شانس'، كه نسبت حاصلضرب

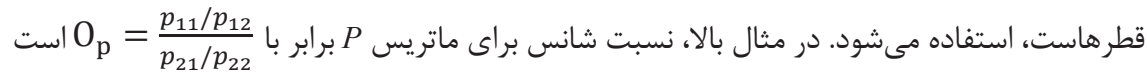

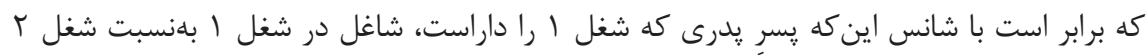

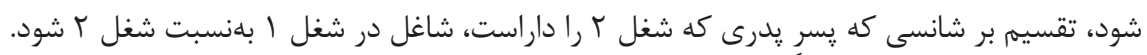

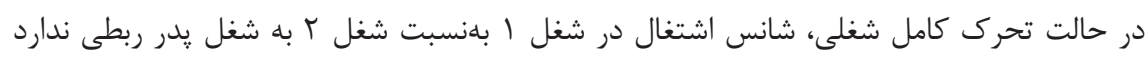

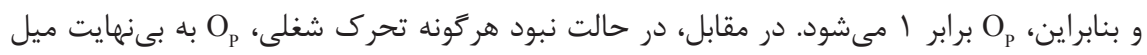

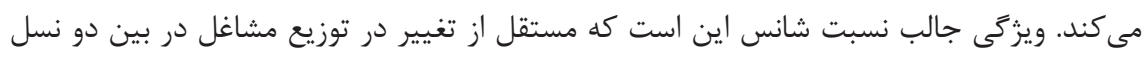

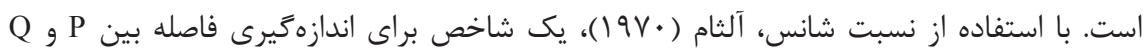

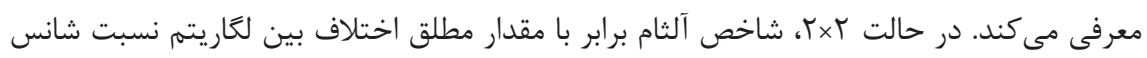
$\mathrm{d}(\mathrm{P}, \mathrm{Q})=\left|\log \left(\mathrm{O}_{\mathrm{P}}\right)-\log \left(\mathrm{O}_{\mathrm{Q}}\right)\right|$

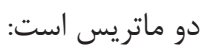

براى حالتى كه ماتريسهاى تغيير حالت r سطر و c ستون داشته باشند، فاصله آلثام از اين راه محاسبه مىشود:

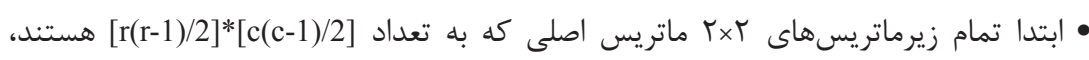
ساخته مىشوند. • فاصله آلثام براى هر زيرماتريس متناظر در P P Q مطابق فرمول (r) محاسبه مىشود: $O_{p_{k}}=\frac{p_{i i} / p_{i j}}{p_{j i} / p_{j j}}, \quad O_{Q_{k}}=\frac{q_{i i} / q_{i j}}{q_{j i} / q_{j j}}, \quad d\left(P_{k}, Q_{k}\right)=\left|\log \left(O_{P_{k}}\right)-\log \left(O_{Q_{k}}\right)\right|$

در مرحله آخر فاصله كلى بين P ب برابر با جذر مجموع مجذورهاى فاصلههاى بين زيرماتريسها

$d(P, Q)=\sqrt{\left[d\left(P_{1}, Q_{1}\right)\right]^{2}+\left[d\left(P_{2}, Q_{2}\right)\right]^{2}+\cdots+\left[d\left(P_{K}, Q_{K}\right)\right]^{2}}$

در فرمول بالا d(P, Q) اختلاف ماتريس P و از نظر همبستكى بين سطر و ستون آنهاست و توسط يك آزمون نسبت درستنمايى خىدو با (r-1)(c-1) درجه آزادى، مىتوان فرض صفر 
d(P,Q) با ضرب كردن

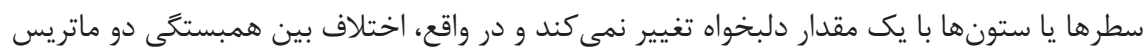

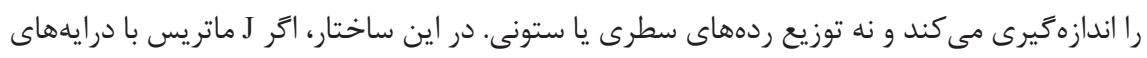

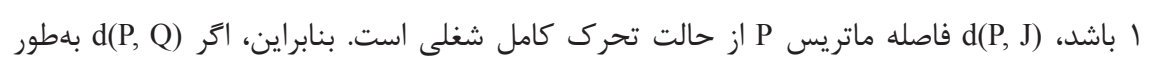

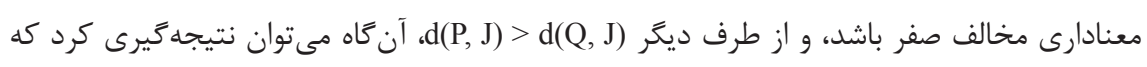
تحرك شغلى در ماتريس Q بيشتر از P است و بالعكس.

\section{دادهها}

دادههاى اصلى اين يزووهش از دو منبع سرشمارى نفوس و مسكن، و طرح نيروى كار مركز آمار

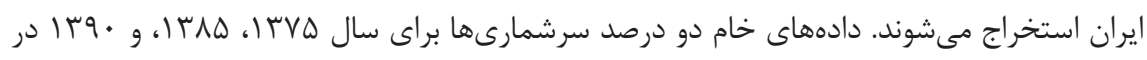

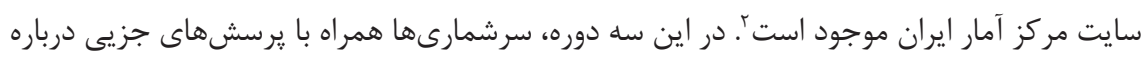

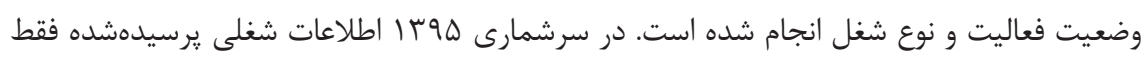

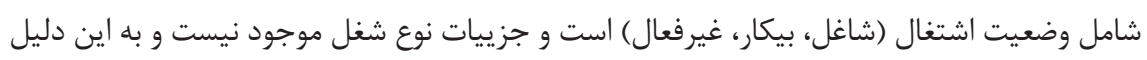

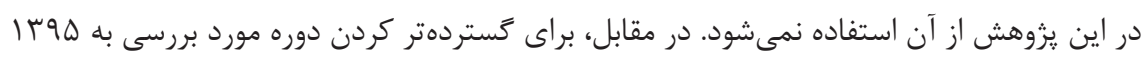

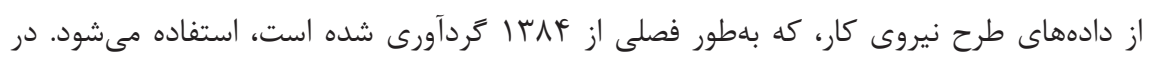

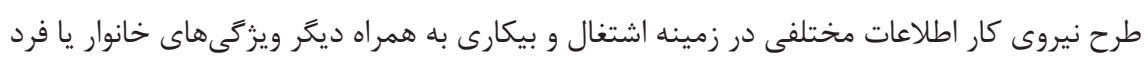

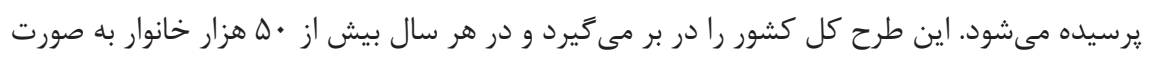

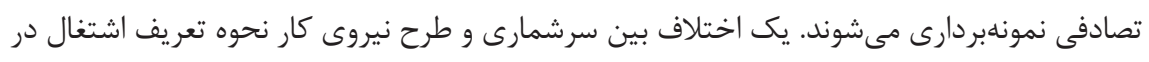

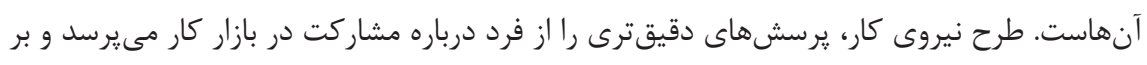

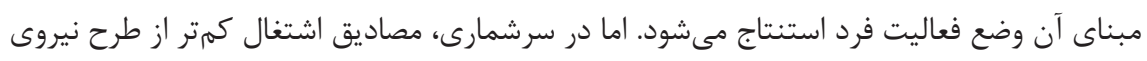

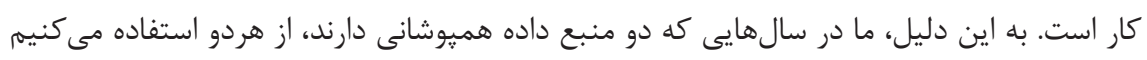
براى مقايسه روندهايى كه هر كدام نتيجه مي دهند.

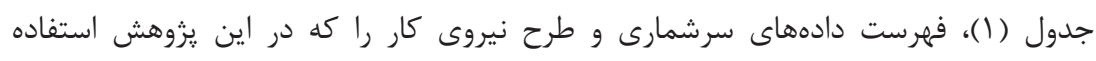

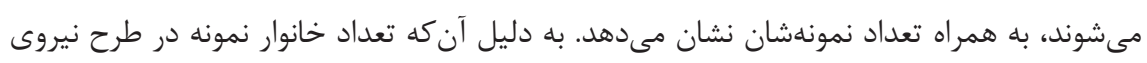

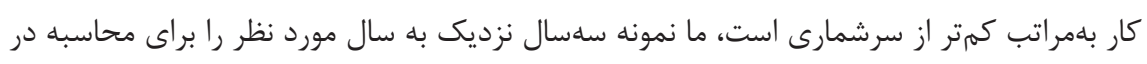


نظر مى گيريم. در نمونه سرشمارىها دست كم اس هزار خانوار با جفت يدر-يسر شاغل وجود دارد كه

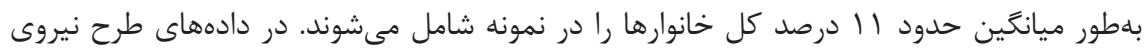

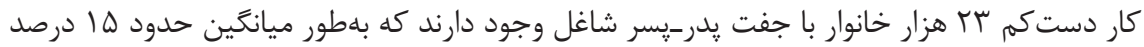
از كل خانوارهاى نمونه را شامل مىشوند. دليل بيشتر بودن نسبت خانوارها در طرح نيروى كار تعريف جامعتر اشتغال در اين طرح نسبت به سرشمارى است. ما مىتوانيم تحرى شغلى را با اين دادهها براى تههار دوره DV

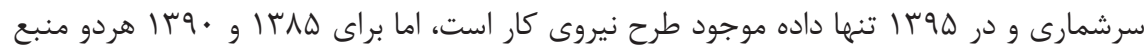

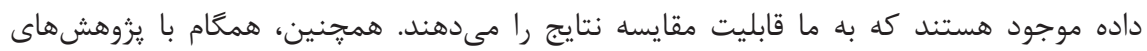
پيشين در ساير كشورهاى درحالتوسعه، براى تخمين تحرك شغلى، نمونه مورد استفاده در تخمين

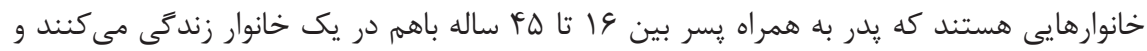
هردو شاغل با كد نوع شغل هستند.

جدول ا: فهرست دادهها و تعداد نمونه آنها

\begin{tabular}{|c|c|c|c|}
\hline تعداد خانوار & تعداد جفت يدر - پيسر & سال & نوع داده \\
\hline rFG9V. & $11 \cdot 19$ & ITVD & \\
\hline rFDVqq & Frr人q & IrAD & سرشمارى \\
\hline GTHEVT & TUVTT & $1 \% q$. & \\
\hline IVAFF. & r. & Ir人\&-Ir人⿻ & \\
\hline $\mid V A F \Delta \Lambda$ & TrGGA & $\mid$ |ґ৭-|rq| & طرح نيروى كار \\
\hline מון שמז & $r \varepsilon \Delta \cdot \Delta$ & 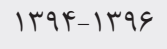 & \\
\hline
\end{tabular}

همانطور كه در مقدمه اشاره شد، يك داده ايدهآل براى تخمين تحرك بيننسلى بايد نوع شغل ֶّر و يسر را در يك بازه سنى مشابه باهم مقايسه كند. اما اين موضوع در دادههاى سطح خانوار مركز آمار ايران و بيشتر كشورهاى درحالتوسعه موجود نيست. يزوهشهايى كه در اين زمينه در ديكر

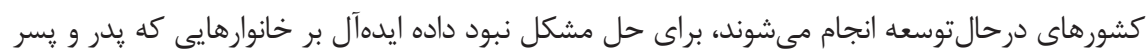

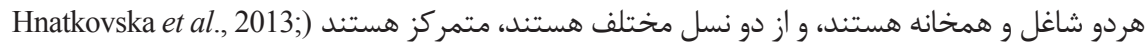
Reddy, 2015; Emran \& Shilpi, 2011; Emran \& Sun, 2015 بلافاصله به يك اريب نمونه منجر مىشود، به دليل اينكه نمونه پدر-يسرهاى همخانه باطور نظاممند 
متفاوت از بقيه هستند، اگر اين اريب نمونه در طول زمان پايدار باشد، مىتواند در تحليل روند، كه

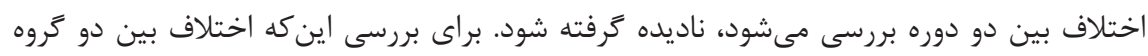
در طول زمان ثابت است يا خير، در نمودار ( (1)، سن، تحصيلات، وضعيت ازدواج، و اندازه خانوار براى خانوارهاى داراى يدر-يسر همخانه با ساير خانوارها مقايسه مىشود. روشن است كه با وجود اختلاف

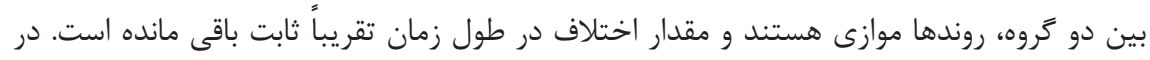
مورد اندازه خانوار مشاهده مىشود كه هر دو كروه شيب منفى دارند، اما براى كروه همخانه شيب

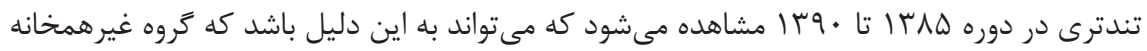
به حد يايين اندازه خانوار نزديك مىشود و بهطور طبيعى، شيب نزديك اين حد كاهش مئ ميابد.

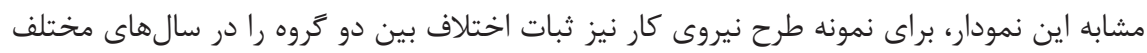

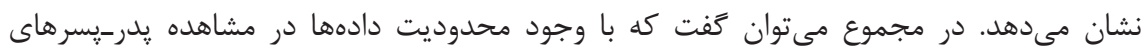
غيرهمخانه، به دليل اينكه فاصله بين خانوارهاى همخانه و غيرهمخانه در طول زمان باثبات است، مى توان براى بررسى روند تحرك شغلى از اين دادهها استفاده شود.
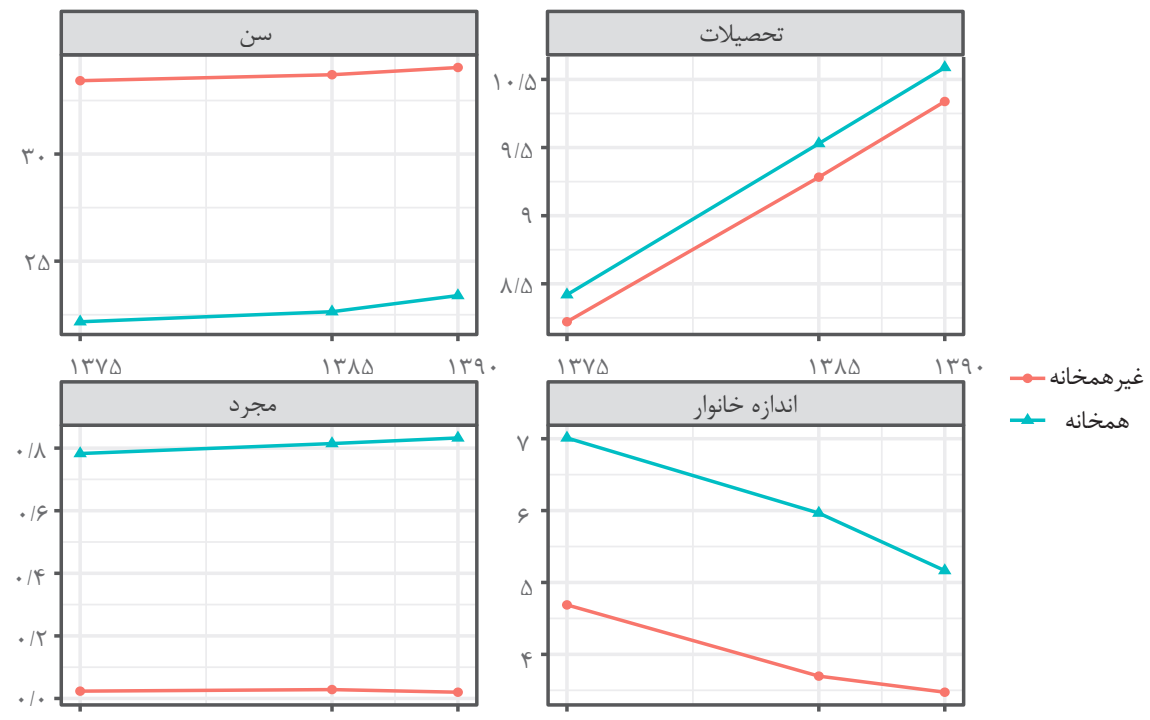
در هر دو منبع داده سرشمارى و طرح نيروى كار، نوع شغل فرد بر مبناى كد جهار رقمى ISCO شغلى استفاده مىشود، تجميع كردن كدهاى جهاررقمى به تعداد محدودى رده شغلى است. براى

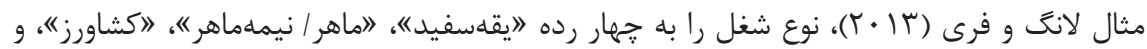
"غيرماهر" تقسيم و بيان مى كنند كه اين جهار دسته به اندازه كافى كلى هستند كه تغيير از يك رده رها به رده ديكر نمايانكر تحرك شغلى بيننسلى باشد. اين تقسيمبندى بر مبناى رقمم اول كد

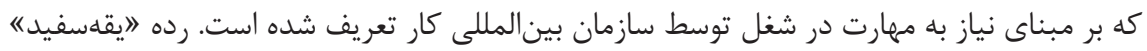

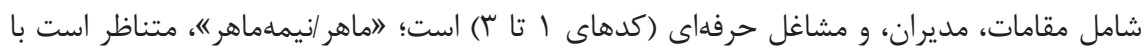

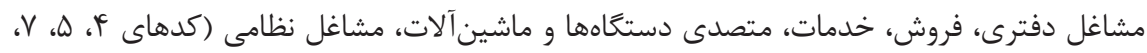

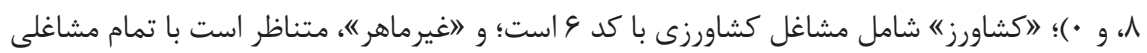

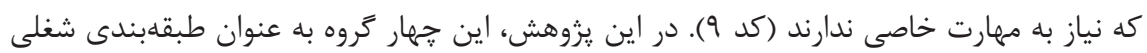
اصلى در نظر گرفته مىشوند.

\section{يافته ها}

در جدول (ז)، ماتريسهاى تغيير وضعيت در طول زمان با استفاده از نمونه پِر-يسرهاى همخانه

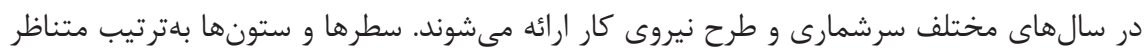

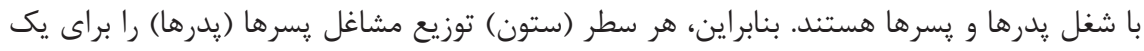

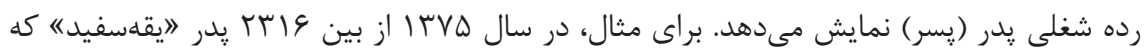

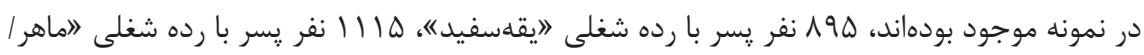

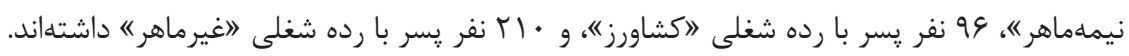


جدول r: ماتريسهاى تغيير وضعيت شغلى از هِر به يّر بر مبناى دادههاى سرشمارى و طرح نيروى كار

\begin{tabular}{|c|c|c|c|c|c|c|c|c|c|}
\hline \multicolumn{4}{|c|}{ طرح نيروى كار } & \multicolumn{5}{|c|}{ سر شمارى } & \\
\hline $\begin{array}{l}3 \\
3 \\
3 \\
3\end{array}$ & 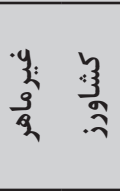 & $\begin{array}{c}\frac{3}{2} \\
\frac{3}{3} \\
\frac{3}{3} \\
3 \\
2\end{array}$ & $\begin{array}{l}: 3: \\
3 \\
3 \\
3 \\
3\end{array}$ & $\begin{array}{c}1 \\
3 \\
3 \\
3 \\
3\end{array}$ & 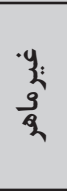 & 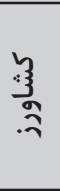 & $\begin{array}{c}\frac{3}{2} \\
\frac{2}{3} \\
3 \\
3 \\
3 \\
3\end{array}$ & $\begin{array}{l}: 9: \\
3 \\
3 \\
3\end{array}$ & $\xi$ \\
\hline
\end{tabular}

|rNA-IrNS

ITVA

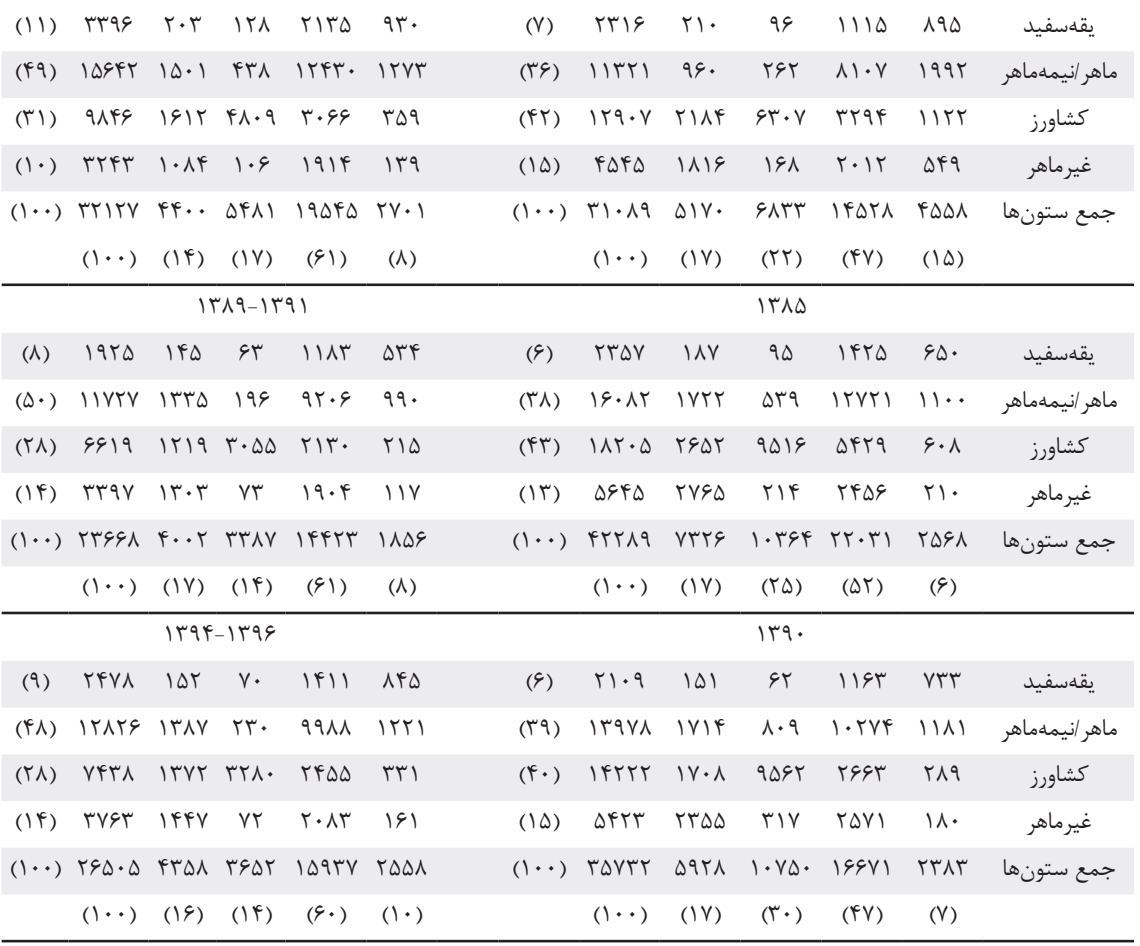

توضيح: اعداد داخل برانتز نشاندهنده درصد جمع سطر/ستون از جمع كل هستند.

با توجه به جدول (r)، مىتوان كفت كه اختلاف زيادى بين ڤدرها و يسرها از نظر توزيع ردههاى

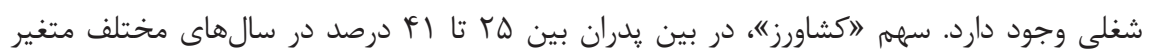

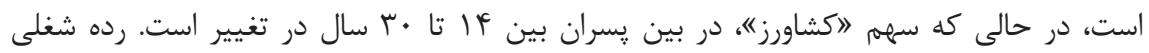




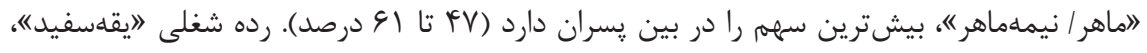

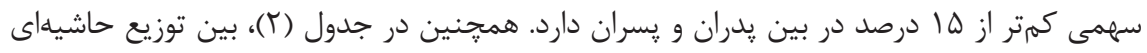

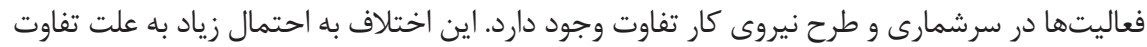
در تعريف اشتغال بين دو طرح و همجنين، تفاوت در فصل آماركيرى است. با توجه به اينكه يوشش سرشمارى شامل تمامى افراد كشور است، يرسشنامه آن كوتاه و تعداد محدودى پرسش درئ درباره وضعيت

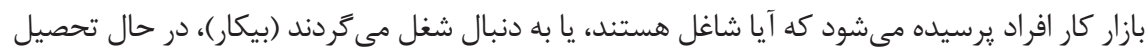

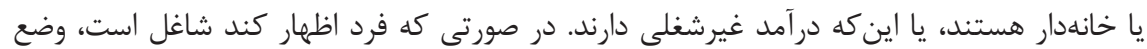

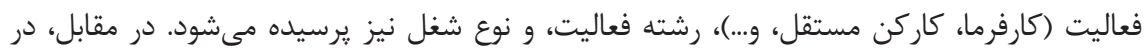

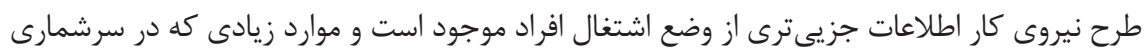

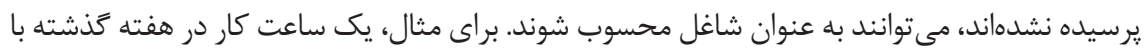

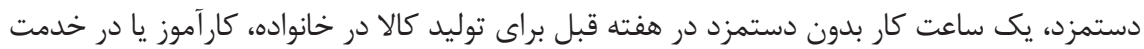
سربازى بودن، داشتن شغل اما غيبت موقت از آن، برخى از مواردى هستند كه در طرح نيروى كار از

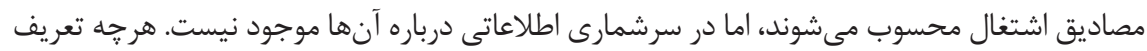
اشتغال جامعتر شود، انتظار مىرود كه تعداد خانوارهايى با پدر و يسر شاغل افزايش يابد. از طرف ديكر،

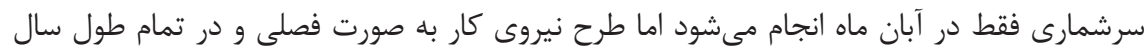

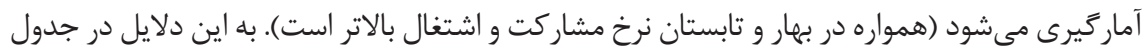
(1)، مشاهده مىشود كه تعداد خانوارهاى همخانه در سرشمارى حدود 1 (ا درصد كل خانوارهاست، اما در طرح نيروى كار حدود ها درصد است. با وجود اين، همانطور كه در بالا اشاره شد، فاصله آلثام

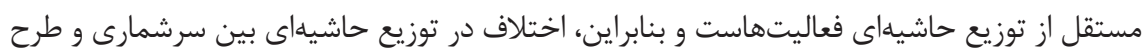

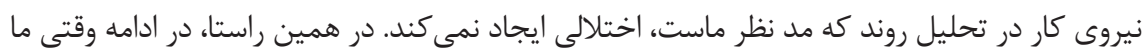

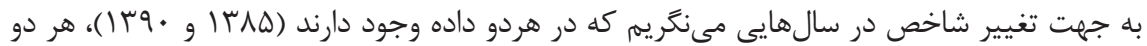

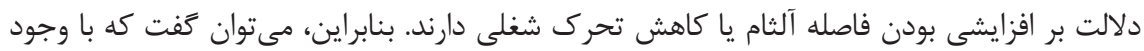

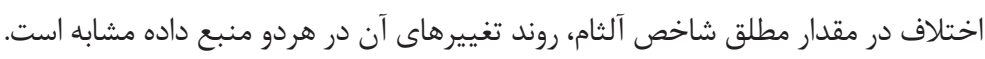

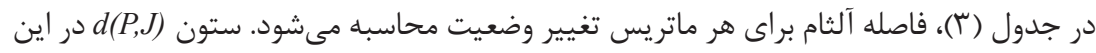
جدول نشاندهنده فاصله ماتريس تغيير وضعيت از ماتريس تحرك كامل شغلى (همه عناصر يكسان) است و ساير ستونها (d), يا فاصله بين دو ماتريس جريان در دو سال مختلف سرشمارى يا طرح

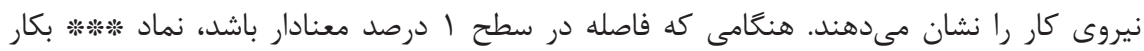


رفته است. همجنين در نمودار (ז)، روند فاصله (d(P,J) از حالت تحرى كامل براى سالهاى مختلف سرشمارى و طرح نيروى كار ترسيم شده است. بر طبق اين نمودار مشاهده مىشود كه مقدار مطلق تحرك شغلى در دادهاى سرشمارى كمتر از طرح نيروى كار تخمين زده مىشود. ممكن است يك

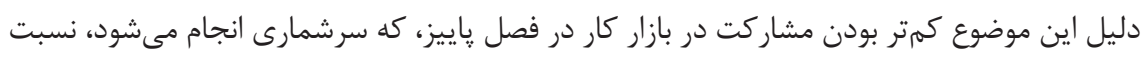

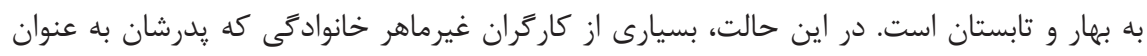
كشاورز طبقهبندى مىشود، در نمونه همخانههاى سرشمارى وجود ندارند، اما در طرح نيروى كار، كه يوشش آن در كل سال است، در نمونه هستند.

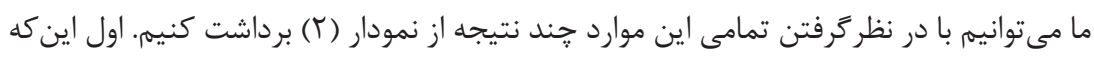

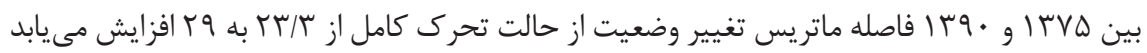
كه به معناى كاهش تحرك شغلى كشور در اين دوره است. بين

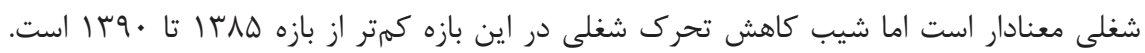

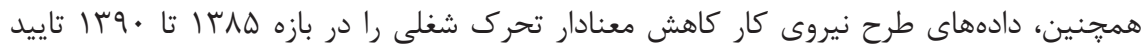

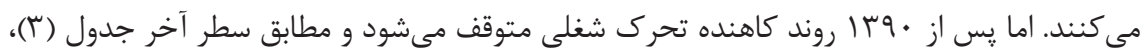
فاصله ماتريسهاى تغيير وضعيت نزديك سالهاى • وسا و هوس ها كم و بىمعناست.

جدول "٪: مقايسه تحر كى شغلى در سالهاى مختلف

\begin{tabular}{|c|c|c|c|c|}
\hline & $d(P, Q)$ & & & سرشمارى \\
\hline irq. & Ir^d & ITVD & $d(P, J)$ & $\mathbf{P}$ \\
\hline 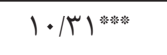 & $\Delta / \Lambda \varphi^{m * a}$ & & 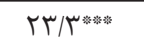 & $I T V D$ \\
\hline \multirow[t]{3}{*}{$g /\left.T\right|^{* * a s}$} & & $\Delta / \Lambda \varphi^{* * *}$ & TQ/TGK" & IrND \\
\hline & 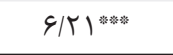 & $1 \cdot /\left.\right|^{\prime *}$ & 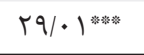 & $1 \% q$. \\
\hline & $d(P, Q)$ & & & طرح نيروى كار \\
\hline Irqf-ı & $|r \wedge q-| r q \mid$ & 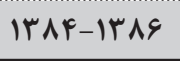 & $\mathbf{d}(\mathbf{P}, \mathbf{J})$ & P \\
\hline T/KY & 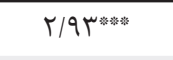 & & 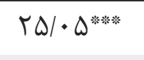 & Ir人E-Ir人s \\
\hline \multirow[t]{2}{*}{$1 / V 1$} & & T/qY & 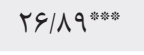 & $|r \wedge q-1 r q|$ \\
\hline & $1 / V 1$ & T/KY糙 & 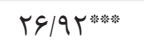 & Irq4-Irqg \\
\hline
\end{tabular}




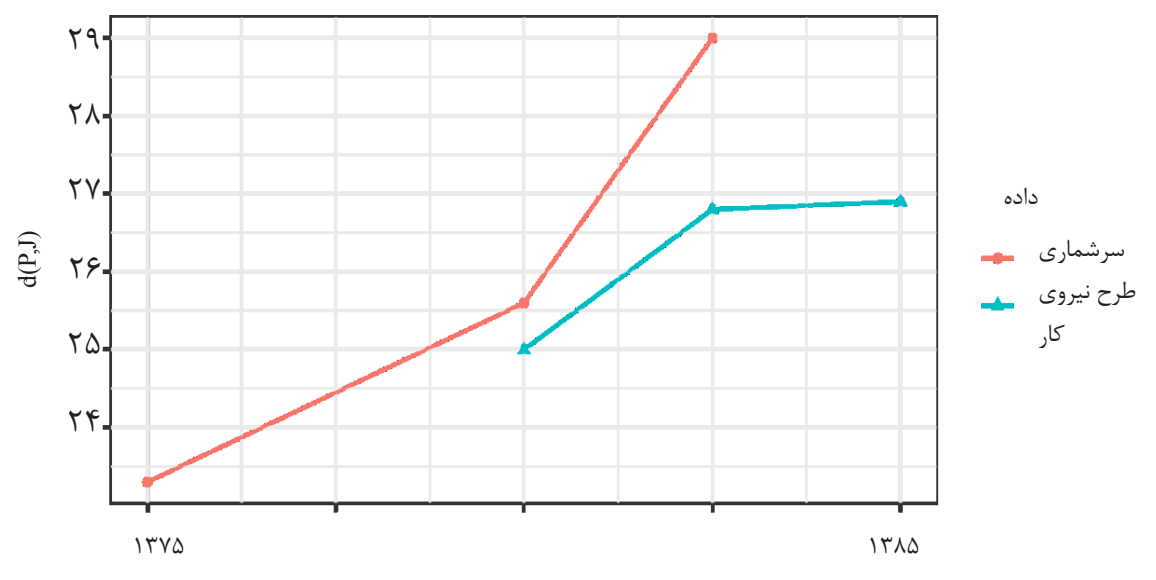

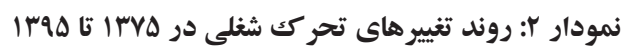

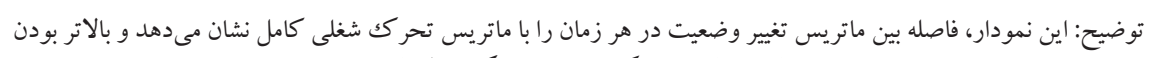

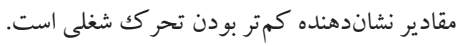

براى بررسى بيشتر تغييرهاى صورتگرفته در تحرك شغلى، در جدول (Y)، فاصله آلثام به عناصر

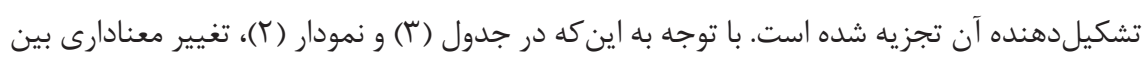

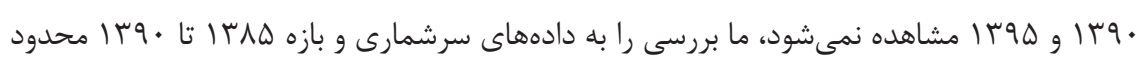

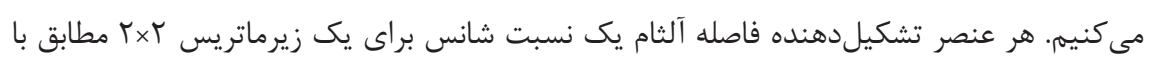

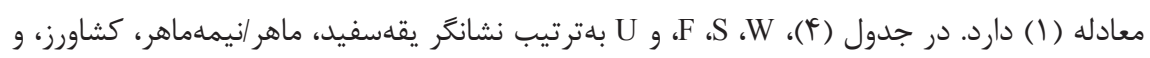
غيرماهر هستند. ستون "انسبت،، نشاندهنده نسبت شانس OOP

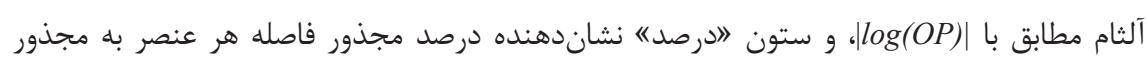

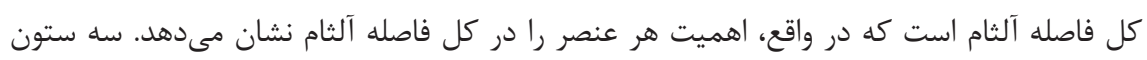

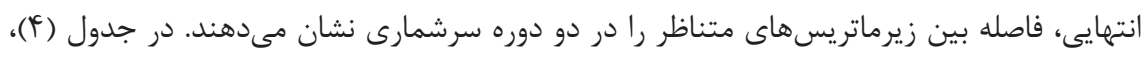

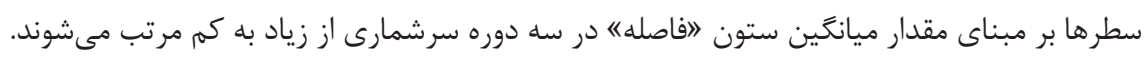

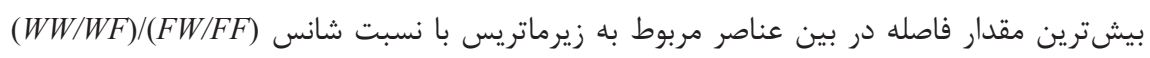
است كه نشاندهنده مزيت نسبى دارا شدن شغل يقهسفيد بلنسبت كشاورز براى كسى است كه يد يدر

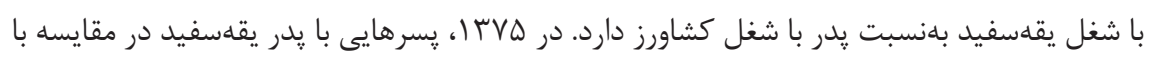

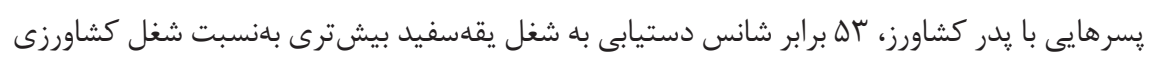




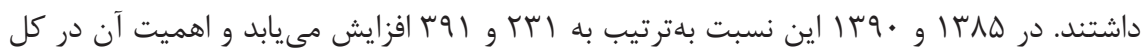
فاصله آلثام بيش از || 1 درصد است. همجنين، مشاهده مى شود كه در بين شش نسبتى كه بيشترين

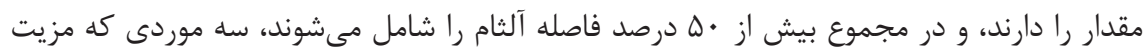

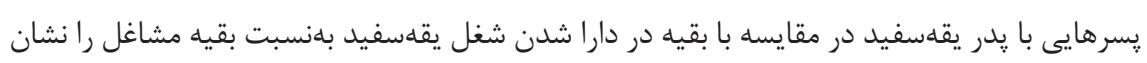

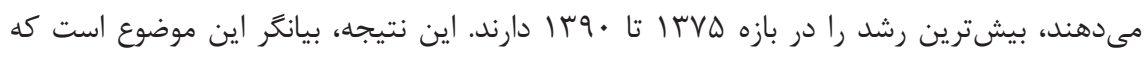

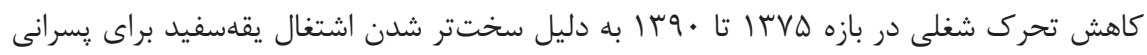

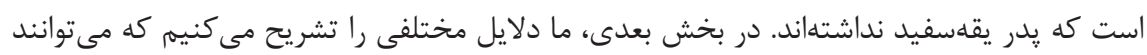
توضيحدهنده كاهش تحرك شغلى در بVD II تا • وسا باشند.

جدول †: عناصر تشكيلدهنده فاصله آلثام در سرشمارىهاى مختلف

\begin{tabular}{|c|c|c|c|c|c|c|c|c|c|c|c|c|}
\hline \multicolumn{3}{|c|}{$\mathrm{d}(\mathbf{P}, \mathbf{Q})$} & \multicolumn{3}{|c|}{ irq. } & \multicolumn{3}{|c|}{ IrAd } & \multicolumn{3}{|c|}{ Irva } & \multirow[b]{2}{*}{ نسبت } \\
\hline $\begin{array}{l}\stackrel{3}{3} \\
\frac{3}{a} \\
\dot{\sigma} \\
\dot{j}\end{array}$ & 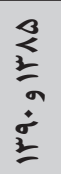 & 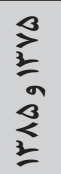 & $\hat{3}$ & $\frac{9}{3}$ & 3 & $\hat{\xi}$ & פֶ? & ; & $\hat{\xi}$ & $\frac{9}{3}$ & ; & \\
\hline$\% / \cdot$ & T/9 & $1 / 4$ & $18 / 9$ & $11 / 9$ & $r q 1 / r$ & $1 \pi / r$ & $9 / r$ & $1 \cdot V / 1$ & $11 / 9$ & $V / 9$ & $\Delta r / F$ & $(\mathrm{WW} / \mathrm{WF}) /(\mathrm{FW} / \mathrm{FF})$ \\
\hline$\cdot / 0$ & $\cdot / r$ & $\cdot / V$ & $9 / 9$ & $V / 9$ & $f Q / \varphi$ & $\Lambda / f$ & $V / F$ & $\{1 / 4$ & $\mid r / r$ & $\Lambda / r$ & $\Delta 9 / T$ & $(\mathrm{SS} / \mathrm{SF}) /(\mathrm{FS} / \mathrm{FF})$ \\
\hline$\cdot / r$ & $\cdot / 1$ & $\cdot 19$ & $V / I$ & $\mathrm{~V} / \mathrm{\Lambda}$ & $\boldsymbol{F N / T}$ & $V / r$ & $9 / 9$ & $r \mathbf{l} / 9$ & $1 \cdot / 4$ & $V / \Delta$ & $\mathrm{FT/V}$ & $(\mathrm{SW} / \mathrm{SF}) /(\mathrm{FW} / \mathrm{FF})$ \\
\hline$\cdot 19$ & $\cdot / r$ & $\cdot / 1$ & $9 / 9$ & $V / \Delta$ & $|F| / 9$ & $9 / \cdot$ & $V / V$ & Fe/9 & $\Lambda / V$ & $9 / 9$ & $r M / r$ & $(\mathrm{FF} / \mathrm{FU}) /(\mathrm{UF} / \mathrm{UU})$ \\
\hline$\mu$. & $\cdot / V$ & $r / 4$ & $N / T$ & $\Lambda / r$ & $q \pi / \Delta$ & N/9 & $V / 9$ & $F \Delta / \Lambda$ & $\Delta / r$ & $\Delta / r$ & $|f /|$ & $(\mathrm{WW} / \mathrm{WU}) /(\mathrm{UW} / \mathrm{UU})$ \\
\hline$r / T$ & 1/9 & $\cdot / r$ & $N / \mathcal{F}$ & $\Lambda / F$ & $9 V / F$ & $9 / 0$ & $9 / 0$ & $r \& / T$ & $V / 1$ & $9 / \pi$ & $T r / T$ & $(\mathrm{WS} / \mathrm{WF}) /(\mathrm{FS} / \mathrm{FF})$ \\
\hline$\cdot / \Delta$ & $\cdot / V$ & $\cdot / r$ & $\Delta / \mathcal{A}$ & $9 / V$ &.$/$ & $\Delta / \Delta$ & 91. &.$/$ & $V / T$ & $9 / \pi$ & $\cdot /$ & $(\mathrm{FS} / \mathrm{FF}) /(\mathrm{US} / \mathrm{UF})$ \\
\hline.$/$ & $\cdot / 4$ & $\cdot / 4$ & $F / 1$ & $\Delta / 9$ & $\cdot / 1$ & $F / D$ & $\Delta / \omega$ & $\cdot / 1$ & $9 / \pi$ & $\Delta / \Lambda$ & $\cdot / 1$ & $(\mathrm{FW} / \mathrm{FF}) /(\mathrm{UW} / \mathrm{UF})$ \\
\hline$r / \Delta$ & $1 / \pi$ & $1 / r$ & $\Delta / A^{\mathcal{A}}$ & $9 / V$ & TA/V & $f / d$ & $\Delta / \mathcal{F}$ & $10 / r$ & r & $r / r$ & $\Lambda / r$ & $(\mathrm{WW} / \mathrm{WU}) /(\mathrm{FW} / \mathrm{FU})$ \\
\hline$\cdot / r$ & $\cdot / 1$ & $\cdot / r$ & $r / 9$ & $4 / 9$ & $\cdot / 1$ & $\Gamma / 9$ & $p / q$ & $\cdot / 1$ & $\varphi / 1$ & $F / V$ & $\cdot 11$ & $(\mathrm{SF} / \mathrm{SU}) /(\mathrm{FF} / \mathrm{FU})$ \\
\hline $1 / \Delta$ & $1 / \pi$ & $\cdot / 4$ & $T / T$ & $\Delta / T$ & $\cdot / 1$ & $r / r$ & $r / 9$ & $\cdot / 1$ & $r / \Delta$ & $r / v$ & $\cdot / r$ & $(\mathrm{WF} / \mathrm{WU}) /(\mathrm{FF} / \mathrm{FU})$ \\
\hline$\cdot / \Delta$ & $\cdot / 1$ & $\cdot / 4$ & $r / r$ & $f / f$ & $9 / \cdot$ & $r / \Lambda$ & $r / r$ & $1 / f$ & $T / V$ & $r / 9$ & $9 / 9$ & $(\mathrm{SW} / \mathrm{SU}) /(\mathrm{UW} / \mathrm{UU})$ \\
\hline$\% /$ & $r / T$ & $1 / 1$ & $f / f$ & $9 / 1$ & $r \cdot / \Lambda$ & $r / r$ & $r / 9$ & $\mathrm{~V} / \cdot$ & $\cdot / 1$ & $r / l$ & $r / 9$ & $(\mathrm{WW} / \mathrm{WF}) /(\mathrm{UW} / \mathrm{UF})$ \\
\hline$\cdot / V$ & $\cdot / 1$ & $\cdot / r$ & $1 / 4$ & $r / s$ & $\Delta / \Delta$ & $T / V$ & $r / r$ & $\Lambda / r$ & $\lessdot /$ & $p / l$ & $V / 9$ & $(\mathrm{SS} / \mathrm{SU}) /(\mathrm{US} / \mathrm{UU})$ \\
\hline
\end{tabular}


ادامه جدول fا: عناصر تشكيلدهنده فاصله آثام در سرشمارىهاى مختلف

\begin{tabular}{|c|c|c|c|c|c|c|c|c|c|c|c|c|}
\hline \multicolumn{3}{|c|}{$\mathbf{d}(\mathbf{P}, \mathbf{Q})$} & \multicolumn{3}{|c|}{ irq. } & \multicolumn{3}{|c|}{ Ir^d } & \multicolumn{3}{|c|}{ Irva } & \multirow[b]{2}{*}{ نسبت } \\
\hline $\begin{array}{l}\stackrel{3}{z} \\
\dot{2} \\
\dot{2} \\
\underline{2}\end{array}$ & $\begin{array}{l}\stackrel{3}{<} \\
\frac{2}{a} \\
\dot{j} \\
\underline{2}\end{array}$ & 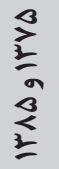 & $\hat{3}$ & 3.9 & 3 & $\hat{3}$ & ?3 & : & $\hat{3}$ & 3.9 & :3. & \\
\hline$\cdot 1 \Lambda$ & $\cdot / 4$ & $1 / r$ & $1 / 1$ & $r / 9$ & $V / l$ & $r / \Lambda$ & $p / r$ & $1 / 9$ & $1 / 1$ & $\Pi / l$ & $F / \Lambda$ & $(\mathrm{WS} / \mathrm{WU}) /(\mathrm{US} / \mathrm{UU})$ \\
\hline$T / T$ & $1 / \cdot$ & $1 / r$ & $r / r$ & $f / F$ & १/• & $1 / V$ & r/r & $\Delta / \Gamma$ & $\cdot / 9$ & $T / T$ & $r / 9$ & $(\mathrm{WW} / \mathrm{WS}) /(\mathrm{UW} / \mathrm{US})$ \\
\hline $1 / \cdot$ & $1 / 0$ & $\cdot 19$ & $\cdot 19$ & $T / T$ & $r / l$ & $T / T$ & $r / \Lambda$ & $9 / 9$ & $1 / 9$ & $\Gamma / \tau$ & $1 / q$ & $(\mathrm{WF} / \mathrm{WU}) /(\mathrm{UF} / \mathrm{UU})$ \\
\hline $1 / \cdot$ & $\cdot / 1$ & $1 / \cdot$ & $1 / 4$ & $r / \mathcal{F}$ & $\Delta / \Delta$ & $1 / V$ & $r / r$ & $\Delta / \Gamma$ & $1 / \cdot$ & $r / \mathcal{F}$ & 虫 & $(\mathrm{WW} / \mathrm{WS}) /(\mathrm{SW} / \mathrm{SS})$ \\
\hline$r / \Delta$ & $\cdot 10$ & $1 / 9$ & $1 / 1$ & $r / 9$ & $\mathrm{~V} / \cdot$ & $1 / V$ & $r / \mathcal{F}$ & $\Delta / \mathcal{F}$ & $\cdot / 4$ & $1 / 4$ & $T / 1$ & $(\mathrm{WW} / \mathrm{WU}) /(\mathrm{SW} / \mathrm{SU})$ \\
\hline$\cdot 1 \Lambda$ & $\cdot / 1$ & $\cdot 19$ & $\cdot 19$ & $T / V$ & $\Gamma / \Lambda$ & $1 / \cdot$ & $r / 9$ & r/9 & $T / T$ & $r / \mathcal{F}$ & $\Delta / 9$ & $(\mathrm{SS} / \mathrm{SU}) /(\mathrm{FS} / \mathrm{FU})$ \\
\hline$\cdot / V$ & $\cdot 19$ & $\cdot / 1$ & $1 / r$ & $r / r$ & $4 / q$ & $1 / 1$ & $r / 9$ & $r / V$ & $1 / \pi$ & $r / \Delta$ & $r / \Delta$ & $(\mathrm{WS} / \mathrm{WU}) /(\mathrm{FS} / \mathrm{FU})$ \\
\hline $1 / 1$ & $\cdot / V$ & $1 / 1$ & $1 / \Delta$ & $r / Q$ & $\Delta / \Lambda$ & $1 / r$ & $r / \Lambda$ & $F / 1$ & $\cdot 10$ & $1 / V$ & $r / \mathcal{T}$ & $(\mathrm{WW} / \mathrm{WS}) /(\mathrm{FW} / \mathrm{FS})$ \\
\hline$\cdot 1 \cdot$ & $\cdot / 1$ & $\cdot / V$ & $\cdot 19$ & $r / \Lambda$ & $\boldsymbol{F} / 1$ & $\cdot 19$ & $r / \cdot$ & $T / \Lambda$ & $1 / 4$ & $r / \Lambda$ & $\varphi / \cdot$ & (SW/SU)/(FW/FU) \\
\hline$\cdot / r$ & $\cdot / \mu$ & $\cdot 19$ & $\cdot / V$ & $r / \Delta$ & $r / \Delta$ & $1 / \pi$ & $r / \Lambda$ & $\varphi /$. & $\cdot / 9$ & $T / T$ & $r / \cdot$ & (SF/SU)/(UF/UU) \\
\hline $\mathrm{r} / \Lambda$ & $1 / 1$ & $\tau / \cdot$ & $r / l$ & $r / r$ & $1 / 1$ & $\cdot 19$ & $r / 4$ & $r / \mathcal{F}$ & $\cdot / \cdot$ & $\cdot / f$ & $1 / r$ & $(\mathrm{WW} / \mathrm{WF}) /(\mathrm{SW} / \mathrm{SF})$ \\
\hline$\cdot / \pi$ & $\cdot / 4$ & $\cdot / T$ & $\cdot / 4$ & $1 / 9$ & $r / 9$ & $\cdot \pi$ & $1 / 0$ & $r / 1$ & $\cdot 10$ & $1 / V$ & $r / r$ & (SW/SF)/(UW/UF) \\
\hline$\cdot 10$ & $\cdot 19$ & $1 / 1$ & $\cdot / \pi$ & $1 / 9$ & $T / T$ & $\cdot / V$ & $T / T$ & $\Pi / \cdot$ & $\cdot / r$ & $1 / 1$ & $1 / V$ & $(\mathrm{FW} / \mathrm{FU}) /(\mathrm{UW} / \mathrm{UU})$ \\
\hline $1 / \cdot$ & $\cdot 10$ & $\cdot 10$ & $\cdot / 1$ & .19 & $1 / 9$ & $\cdot / \mu$ & $1 / 4$ & $r / 1$ & $\cdot / V$ & $1 / 9$ & $r / 9$ & $(\mathrm{SS} / \mathrm{SF}) /(\mathrm{US} / \mathrm{UF})$ \\
\hline$T / V$ & $1 / V$ & $1 / 1$ & $\cdot / 1$ & $\cdot / 1$ & $1 / 0$ & $\cdot / 1$ & $\cdot 19$ & $\cdot 19$ & $\cdot / V$ & $r / \cdot$ & $\cdot / \mathbb{q}$ & $(\mathrm{WS} / \mathrm{WF}) /(\mathrm{SS} / \mathrm{SF})$ \\
\hline$\cdot / 1$ & $1 / \cdot$ & $1 / 1$ & $\cdot / 1$ & $\cdot / V$ & $1 / 4$ & $\cdot / \mathbb{f}^{\mathrm{f}}$ & $1 / V$ & $r / \mu$ & $\cdot 11$ & $\cdot 19$ & $1 / 4$ & (FS/FU)/(US/UU) \\
\hline $1 / \pi$ & $1 / 4$ & $\cdot / 1$ & $\cdot / \cdot$ & $\cdot / r$ & $\cdot 19$ & $\cdot / 1$ & $1 / \cdot$ & $1 / 9$ & $\cdot / 4$ & $1 / \cdot$ & $1 / V$ & (WF/WU)/(SF/SU) \\
\hline $1 / V$ & $1 / 1$ & $\cdot 19$ & $\cdot / \pi$ & $1 / V$ & $r / r$ & $\cdot / \cdot$ & $\cdot 10$ & $1 / r$ & $\cdot / \cdot$ & $\cdot / 1$ & $1 / \cdot$ & (WS/WF)/(US/UF) \\
\hline$\cdot / 4$ & $\cdot / \mu$ & $\cdot / 1$ & $\cdot / 1$ & .19 & $1 / 9$ & $\cdot 1 \cdot$ & $\cdot 10$ & $1 / r$ & $\cdot / \cdot$ & $\cdot / f$ & $1 / r$ & $(\mathrm{FW} / \mathrm{FS}) /(\mathrm{UW} / \mathrm{US})$ \\
\hline $1 / 4$ & $\cdot / 4$ & $1 / \cdot$ & $\cdot /$ & $\cdot 10$ & $1 / \pi$ & $\cdot 1$ & $\cdot / 1$ & $1 / \cdot$ & $\cdot / 4$ & $\cdot 19$ & $\cdot 19$ & $(\mathrm{WS} / \mathrm{WU}) /(\mathrm{SS} / \mathrm{SU})$ \\
\hline$\cdot 11$ & $\cdot 19$ & $\cdot / 1$ & $\cdot / \cdot$ & $\cdot / 1$ & $1 / 1$ & $\cdot / \cdot$ & $\cdot 10$ & $\cdot / 1$ & $\cdot 11$ & $\cdot / V$ & $\cdot / V$ & $(\mathrm{SW} / \mathrm{SS}) /(\mathrm{FW} / \mathrm{FS})$ \\
\hline $1 / r$ & $1 / \cdot$ & $\cdot / r$ & $\cdot / 1$ & $1 / \cdot$ & $1 / 9$ & $\cdot 1 \cdot$ & $\cdot / \cdot$ & $1 / \cdot$ & $\cdot / \cdot$ & $\cdot / r$ & $\cdot / 9$ & $(\mathrm{SW} / \mathrm{SS}) /(\mathrm{UW} / \mathrm{US})$ \\
\hline $1 \cdot / \pi$ & $9 / \pi$ & $\Delta / 9$ & $1 \cdots 1$ & rq/. & & $1 \cdots 1$ & $r \Delta / \varphi$ & & $1 \cdots 1$ & א/r & & مجموع \\
\hline
\end{tabular}

توضيح: در اين جدول W نشانخر طبقه شغلى "يقه سفيد)، S نشانگر (ماهر / نيمهماهر)، F نشانخر (اكشاورز)، و U نشانكر "(غيرماهر) هستند. 
در اين بخش، به بحث و بررسى عوامل مختلفى مى يردازيم كه مىتوانند توضيحدهنده تغييرهاى

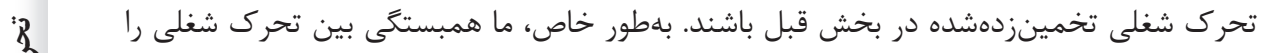

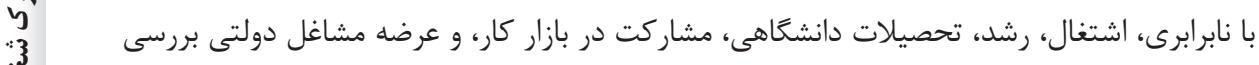

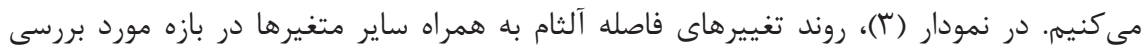

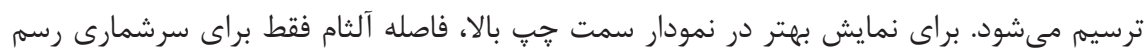
شده است و براى سال هوبا فرض شده است كه تغييرى در اين فاصله نسبت به سال •وب ا ايجاد نشده است.
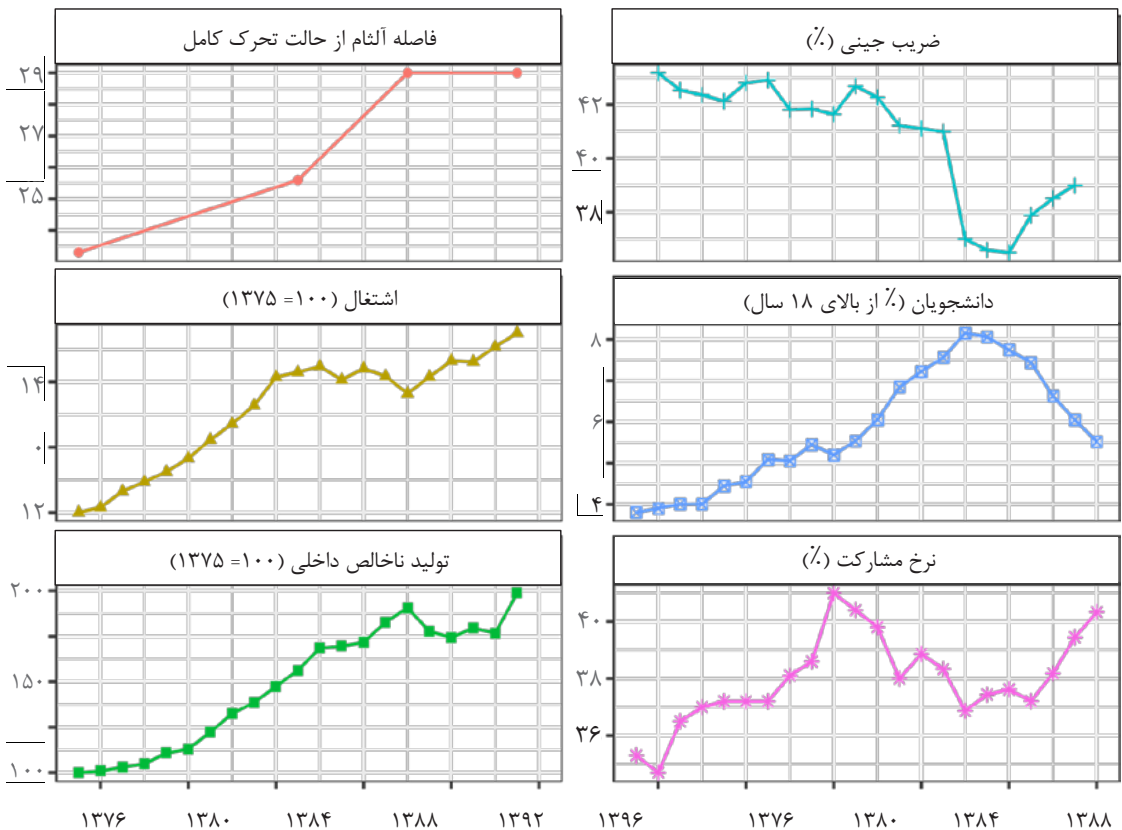

ITVG

\section{نمودار "ّ: روند تغيير هاى فاصله آثام}

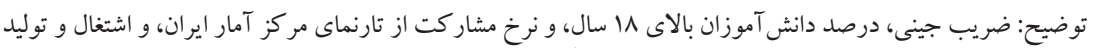

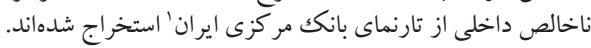


يزوهش هاى فراوانى حاكى ازاثر منفى نابر ابرى در آمدى بر تحر كاجتماعى هستند كهبهمنحنى كاتسبى'

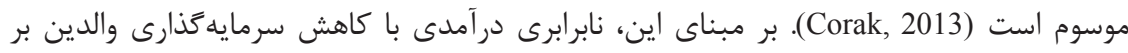
تحصيل فرزندان موجب كاهش تحرك اجتماعى مىشود (Solon, 1999). البته انتظار مىرود كه اين اثر در بلندمدت اتفاق بيافتد و به نظر نمىرسد كه كاهش شديد تحرك شغلى در بازه كوتاه هی

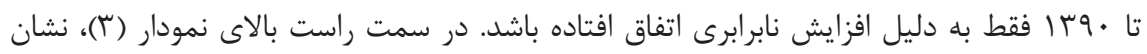

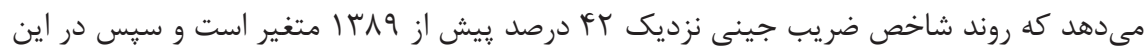

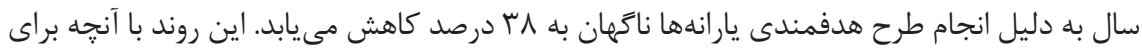

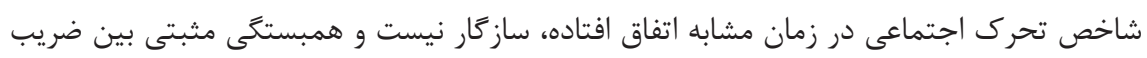
جينى و روند تحرك شغلى مشاهده نمىشود. البته نبود همبستگى مثبت بين سرىزمانى دو متغير

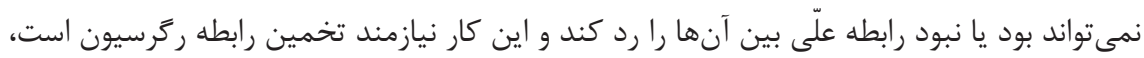

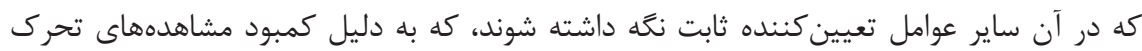
شغلى در اين يزوهش امكانيذير نيست.

\section{رشد بدون اشتغال و اشتغال بدون رشد}

دو عامل ديخر كه مىتوانند تحرك شغلى را تحت تاثير قرار دهند، رشد اقتصادى و ايجاد شغل

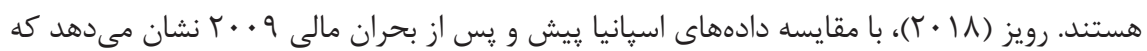

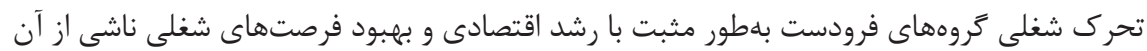

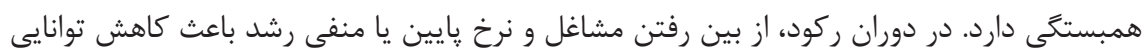

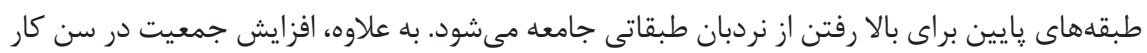
بدون افزايش متناسب رشد و ايجاد اشتغال مىتواند به كاهش تعداد فرصتهاى شغلى براى نسل هاى جديد و در نتيجه، كاهش تحرك شغلى منجر شود. براى بررسى ارتباط اين عوامل با روند تحرى

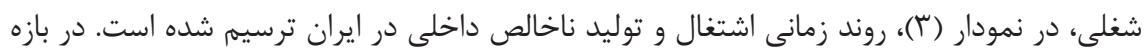


زمانى مورد بررسى، اقتصاد ايران شاهد دورههاى مختلفى از منظر رشد و اشتغال است. از لهV

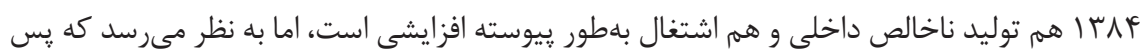

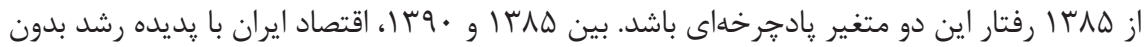

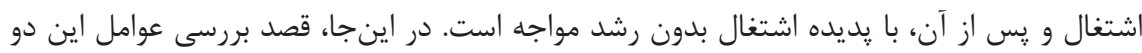

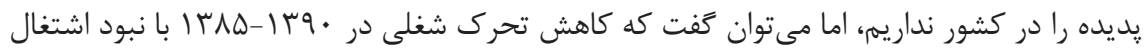

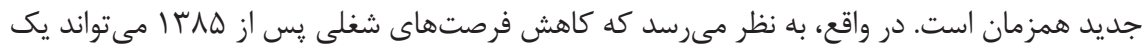

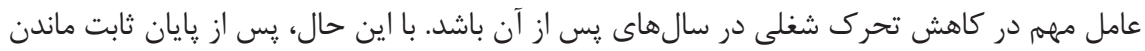

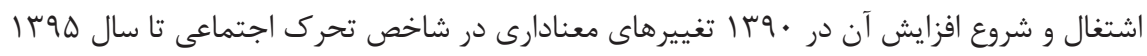
ديده نمىشود كه اين موضوع مىتواند به دليل ركود در اين دوران باشد.

\section{افزايش تعداد دانش آموختكًان دانشعَاهى}

يديده ديگرى كه در دوره مورد بررسى در ايران اتفاق افتاده است، افزايش بىسابقه دانشجويان

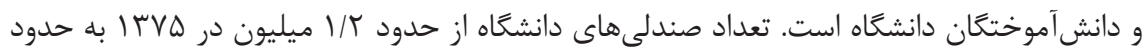

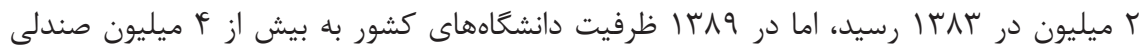

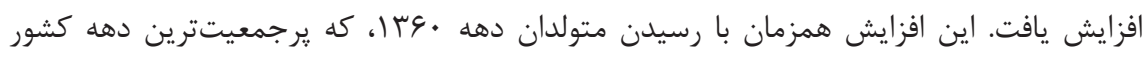
بهشمار مىروند، به سن تحصيل در دانشعاه است، اما با وجود اين، رشد افزايش در ظرفيت دانشعاهها بالاتر از رشد جمعيت در اين دوره است. در نمودار (ب)، مشاهده مىشود كه سهم دانشجويان در

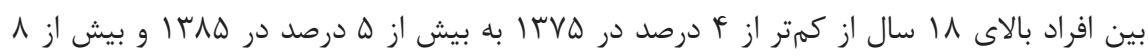

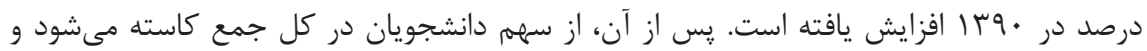
علت اصلى آن را مىتوان در دانشآموخته شدن متولدان اوايل دهه • عسا (كروه قله تولد) دانست.

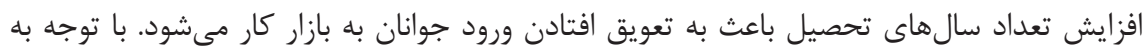

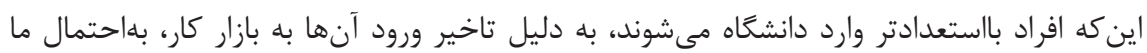

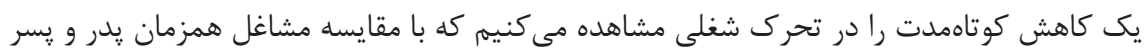

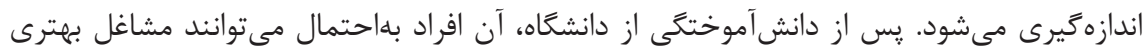
بلهنبت افراد كمسوادتر كسب كنند و بنابراين، انتظار مىرود كه تحرى شغلى قدرى افزايش يابد يا

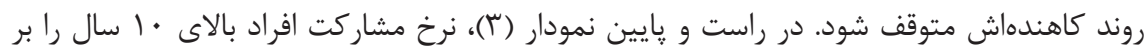
مبناى كزارشهاى مركز آمار ايران نشان مى دهد. بهروشنى مشاهده ميىشود كه افزايش دانش دانشجويان 


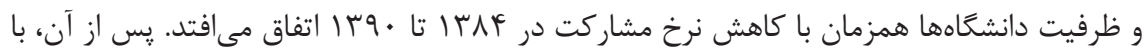

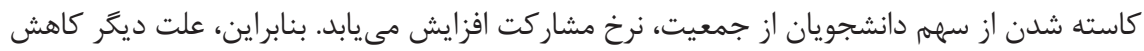
تحرك شغلى يس از سال ه^ها تاخير در ورود به بازار كار فرزندان باستعدادتر به دليل اشتغال

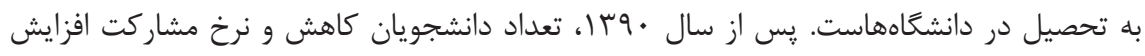
مى يابد، اما تحرك شغلى تقريباً ثابت مى دماند.

\section{عرضه ثابت مشاغل بخش عمومى}

به دليل قوانين بازار كار در ايران كه بيشتر به نفع كارگران نوشته شده است، دستيابى به مشاغل

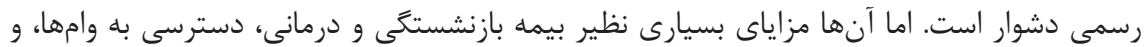
خدمات مختلف را براى كارگران به ارمغان مى آورند. در عمل، بنگاههاى خصوصى به دليل هزينهزي

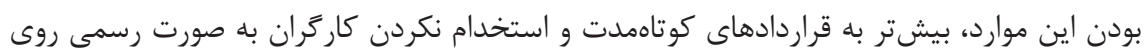

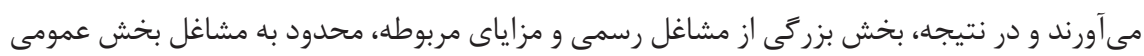
مىشود. كشاورز حداد و علويان قوانينى (1/1)، نشان مىدهند كه با كنترل تحصيل و تجربه، بلهور معنادارى دستمزد در ايران در مشاغل بخش عمومى بالاتر از بخش خصوصى است و تبعيض جنسيتى دستمزد در بخش عمومى وجود ندارد. 


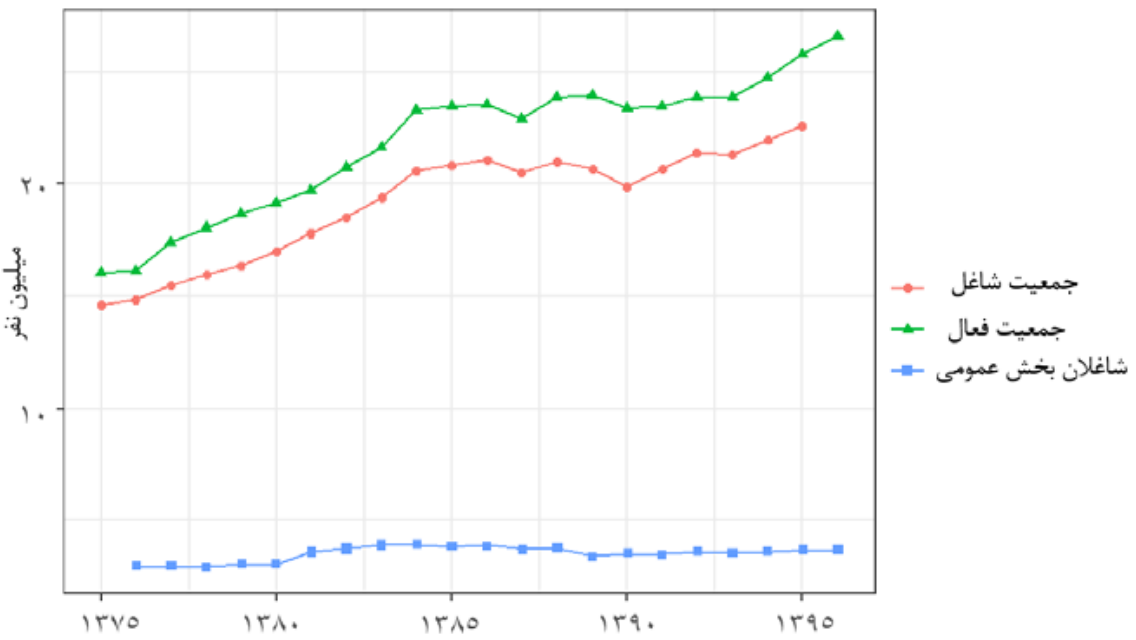

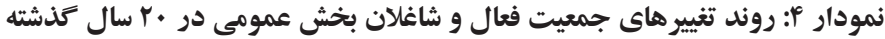

منبع: مركز آمار ايران

با وجود اين كه بالاتر بودن حقوق و مزايا در بخش عمومى انخَيزه بزركى در بسيارى از افراد براى

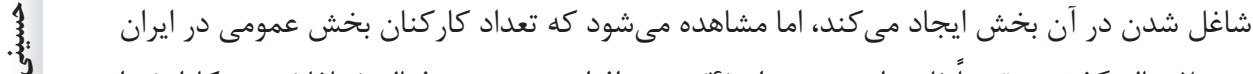

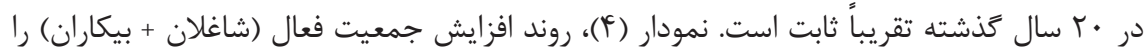
به همراه تغييرهاى شاغلان بخش عمومى به تصوير مى كشد. مشاهده مىشود كه با وجود افزايش زياد

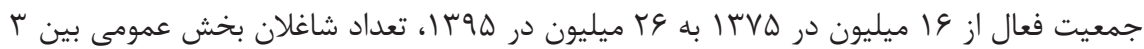

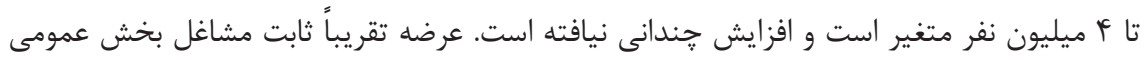

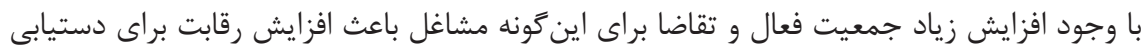

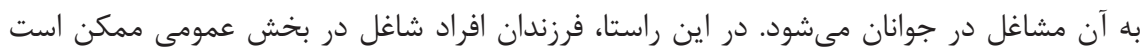

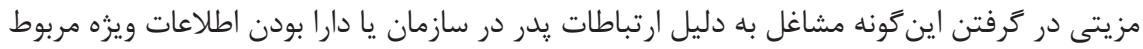

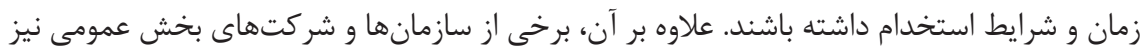
مقررات ويزهاى براى استخدام فرزندان كارمندان خود دارند. 
براى بررسى دقيقتر اين موضوع كه آيا فاصله فزاينده بين جمعيت فعال و اشتغال بخش عمومى موجب

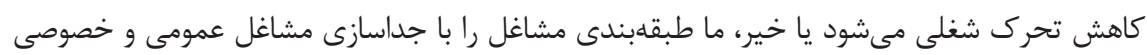
دوباره تعريف مى كنيم. با توجه به اين كه طبقههاى "كشاورز" و "غيرماهر "خارج از حيطه مشاغل عمومى قرار مى گيرند، ما دو كروه "يقهسفيد" و "ماهر اغيرماهر" را باهم تركيب، و بر مبناى عمومى يا خصوصى

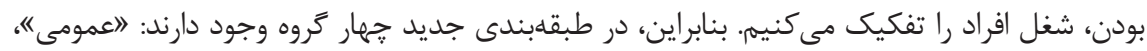

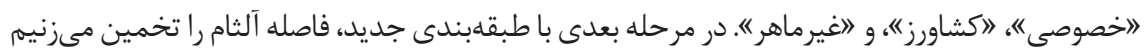

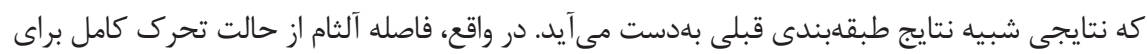
دادههاى سرشمارى در سال فV TM/T

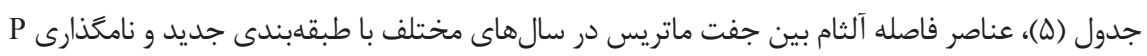

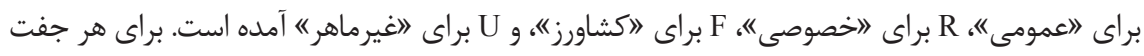

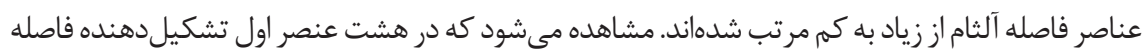

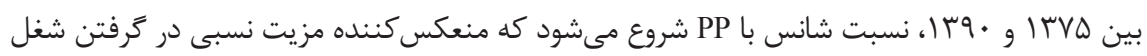
"اعمومى" بلنسبت ديخر مشاغل براى يسرى است كه يدرش شغل "اعمومى" بلنسبت ديخر مشاغل دارد.

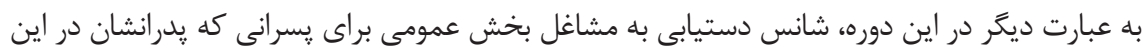

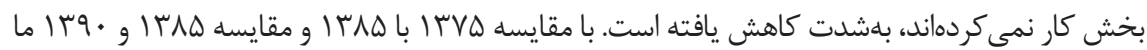

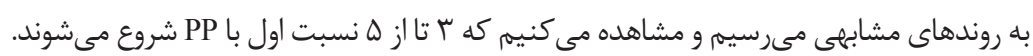

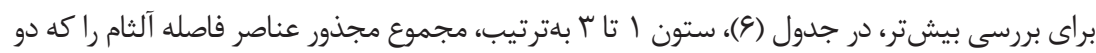
عنصر اول آنها P (عمومى)، R (خصوصى)، و F (كشاورز) باشند، نشان مي بدهد. هركدام از اين عبارتهات

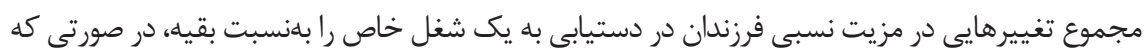

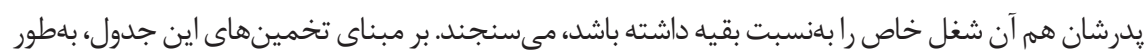
روشن مىتوان كفت كه با وجود تغيير ناجيز عبارتهاى مربوط به مشاغل "خصوصى" و "اكشاورز"، عبارت

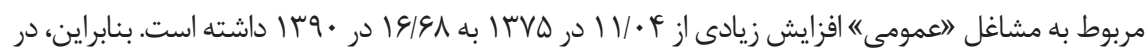
مجموع مى توان كَفت كه ثابت باقى ماندن تعداد مشاغل بخش عمومى و نبود مشاغل با كيفيت مشابه در بخش

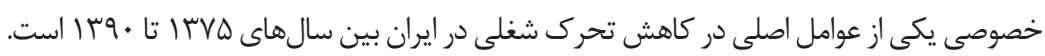


جدول ه: عناصر تشكيل دهنده فاصله آلثام بين سرشمارىهاى مختلف

\begin{tabular}{|c|c|c|c|c|c|c|c|c|c|}
\hline \multirow[b]{2}{*}{ 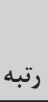 } & \multicolumn{3}{|c|}{ P: $\mid r q_{+}, Q: \| r v \Delta$} & \multicolumn{3}{|c|}{$P: I r \wedge \Delta, Q: I r \vee \Delta$} & \multicolumn{3}{|c|}{ P: $\| r q \cdot, Q: I r \wedge \Delta$} \\
\hline & & نسبت & فاصله & & نسبت & فاصله & & نسبت & فاصله \\
\hline 1 & $(\mathrm{PP} / \mathrm{PF}) /(\mathrm{UP} / \mathrm{UF})$ & $9 / 1$ & $\mathrm{r} / \Lambda$ & (PP/PU)/(UP/UU) & $1 / V$ & $1 / 1$ & $(\mathrm{PR} / \mathrm{PF}) /(\mathrm{FR} / \mathrm{FF})$ & $9 / \pi$ & $r / 9$ \\
\hline r & $(\mathrm{PP} / \mathrm{PF}) /(\mathrm{FP} / \mathrm{FF})$ & $9 / 0$ & $r / \Lambda$ & $(\mathrm{FR} / \mathrm{FU}) /(\mathrm{UR} / \mathrm{UU})$ & $1 / V$ & $1 / \cdot$ & $(\mathrm{PP} / \mathrm{PF}) /(\mathrm{FP} / \mathrm{FF})$ & $9 /$. & $r / 9$ \\
\hline r & (PP/PU)/(UP/UU) & $\Delta / \Delta$ & $r / 4$ & $(\mathrm{FP} / \mathrm{FU}) /(\mathrm{UP} / \mathrm{UU})$ & 1/9 & $\cdot 19$ & $(\mathrm{PP} / \mathrm{PF}) /(\mathrm{RP} / \mathrm{RF})$ & 91. & r/s \\
\hline f & $(\mathrm{PP} / \mathrm{PF}) /(\mathrm{RP} / \mathrm{RF})$ & $\varphi / \Lambda$ & $r / l$ & (PP/PR)/(FP/FR) & $1 / 0$ & $\cdot / 1$ & $(\mathrm{PR} / \mathrm{PF}) /(\mathrm{RR} / \mathrm{RF})$ & $\Delta / V$ & $\Gamma / \Delta$ \\
\hline$\Delta$ & (PP/PR)/(UP/UR) & $r / \Delta$ & $\mu /$ & $(\mathrm{PP} / \mathrm{PU}) /(\mathrm{RP} / \mathrm{RU})$ & $1 / 0$ & $\cdot 1 \Lambda$ & $(\mathrm{PP} / \mathrm{PF}) /(\mathrm{UP} / \mathrm{UF})$ & $r / \Delta$ & $r / \cdot$ \\
\hline 4 & (PP/PU)/(FP/FU) & $r /$. & $T / V$ & $(\mathrm{FF} / \mathrm{FU}) /(\mathrm{UF} / \mathrm{UU})$ & $1 / 0$ & $\cdot / 1$ & $(\mathrm{PR} / \mathrm{PF}) /(\mathrm{UR} / \mathrm{UF})$ & $r / T$ & $r / 9$ \\
\hline v & (PP/PU)/(RP/RU) & $r / 9$ & $r / \Delta$ & $(\mathrm{PF} / \mathrm{PU}) /(\mathrm{UF} / \mathrm{UU})$ & $1 / 0$ & $\cdot / \Lambda$ & $(\mathrm{PR} / \mathrm{PU}) /(\mathrm{FR} / \mathrm{FU})$ & $1 / 4$ & $\cdot 19$ \\
\hline$\wedge$ & $(\mathrm{PP} / \mathrm{PR}) /(\mathrm{FP} / \mathrm{FR})$ & $r / 4$ & $r / f$ & (PP/PR)/(UP/UR) & $1 / 4$ & $\cdot / \mathrm{V}$ & (PP/PU)/(FP/FU) & $1 / \pi$ & $\cdot 19$ \\
\hline 9 & $(\mathrm{PR} / \mathrm{PF}) /(\mathrm{RR} / \mathrm{RF})$ & $r / 4$ & $1 / V$ & (PP/PR)/(RP/RR) & $1 / 4$ & $\cdot / V$ & (PP/PU)/(RP/RU) & $1 / T$ & $\cdot / 4$ \\
\hline 1 . & (RP/RR)/(UP/UR) & $r / \Gamma$ & $1 / 9$ & $(\mathrm{PP} / \mathrm{PF}) /(\mathrm{RP} / \mathrm{RF})$ & $1 / \pi$ & $\cdot 1 \Delta$ & (PR/PU)/(RR/RU) & $1 / \pi$ & $\cdot \pi$ \\
\hline 11 & (PP/PR)/(RP/RR) & $\mathrm{r} / \cdot$ & $1 / 4$ & $(\mathrm{RF} / \mathrm{RU}) /(\mathrm{UF} / \mathrm{UU})$ & $1 / \mu$ & $\cdot 10$ & $(\mathrm{RR} / \mathrm{RU}) /(\mathrm{FR} / \mathrm{FU})$ & $1 / 1$ & $\cdot \pi$ \\
\hline it & $(\mathrm{PR} / \mathrm{PF}) /(\mathrm{FR} / \mathrm{FF})$ & $1 / 9$ & $1 / \%$ & $(\mathrm{PR} / \mathrm{PU}) /(\mathrm{UR} / \mathrm{UU})$ & $1 / 4$ & $\cdot / 4$ & (FP/FR)/(UP/UR) & $1 / 1$ & $\cdot \pi$ \\
\hline$\pi$ & (PR/PU)/(RR/RU) & $1 / 1$ & $1 / 1$ & (PP/PF)/(UP/UF) & $1 / 4$ & $\cdot / \mu$ & (PP/PR)/(UP/UR) & $1 / 1$ & $\cdot \pi$ \\
\hline if & $(\mathrm{RP} / \mathrm{RR}) /(\mathrm{FP} / \mathrm{FR})$ & $1 / V$ & $1 / \cdot$ & $(\mathrm{PF} / \mathrm{PU}) /(\mathrm{RF} / \mathrm{RU})$ & $1 / 4$ & $\cdot \pi$ & $(\mathrm{RR} / \mathrm{RF}) /(\mathrm{FR} / \mathrm{FF})$ & $1 / 1$ & $\cdot / 4$ \\
\hline 10 & (RP/RU)/(UP/UU) & $1 / 0$ & $\cdot 19$ & (RP/RU)/(UP/UU) & $1 / 1$ & 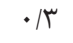 & $(\mathrm{RP} / \mathrm{RU}) /(\mathrm{FP} / \mathrm{FU})$ & $1 / 1$ & $\cdot 11$ \\
\hline 19 & $(\mathrm{PR} / \mathrm{PF}) /(\mathrm{UR} / \mathrm{UF})$ & $1 / \Delta$ & $\cdot 1 \mathrm{~A}$ & $(\mathrm{RR} / \mathrm{RU}) /(\mathrm{UR} / \mathrm{UU})$ & $1 / 1$ & $\cdot / \mu$ & $(\mathrm{RF} / \mathrm{RU}) /(\mathrm{FF} / \mathrm{FU})$ & $1 / 1$ & $\cdot 11$ \\
\hline IV & $(\mathrm{RP} / \mathrm{RF}) /(\mathrm{UP} / \mathrm{UF})$ & $1 / 4$ & $\cdot / V$ & $(\mathrm{FR} / \mathrm{FF}) /(\mathrm{UR} / \mathrm{UF})$ & $1 / 1$ & $\cdot / 4$ & (PP/PR)/(RP/RR) & $1 / \cdot$ & $\cdot 11$ \\
\hline 11 & $(\mathrm{FP} / \mathrm{FU}) /(\mathrm{UP} / \mathrm{UU})$ & $1 / 4$ & $\cdot 19$ & $(\mathrm{PP} / \mathrm{PF}) /(\mathrm{FP} / \mathrm{FF})$ & $1 / 1$ & $\cdot / r$ & (RP/RR)/(UP/UR) & $1 / \cdot$ & $\cdot 11$ \\
\hline 19 & $(\mathrm{RP} / \mathrm{RF}) /(\mathrm{FP} / \mathrm{FF})$ & $1 / 4$ & $\cdot 19$ & (PP/PU)/(FP/FU) & $1 / 1$ & $\cdot / r$ & $(\mathrm{RP} / \mathrm{RF}) /(\mathrm{FP} / \mathrm{FF})$ & $1 / \cdot$ & $\cdot / \cdot$ \\
\hline$r \cdot$ & $(\mathrm{FP} / \mathrm{FR}) /(\mathrm{UP} / \mathrm{UR})$ & $1 / \pi$ & $\cdot 19$ & $(\mathrm{RP} / \mathrm{RR}) /(\mathrm{FP} / \mathrm{FR})$ & $1 / 1$ & $\cdot 11$ & (PP/PR)/(FP/FR) & $1 / \cdot$ & $\cdot 11$ \\
\hline rI & $(\mathrm{FF} / \mathrm{FU}) /(\mathrm{UF} / \mathrm{UU})$ & $1 / \pi$ & $\cdot 19$ & $(\mathrm{PR} / \mathrm{PU}) /(\mathrm{RR} / \mathrm{RU})$ & $1 / 1$ & $\cdot / 1$ & (RF/RU)/(UF/UU) & $1 / \cdot$ & $\cdot 11$ \\
\hline Tr & (PR/PU)/(UR/UU) & $1 / \pi$ & $\cdot / 4$ & (FP/FF)/(UP/UF) & $1 / 1$ & $\cdot / 1$ & (RP/RR)/(FP/FR) & .19 & $\cdot / r$ \\
\hline זr & $(\mathrm{PR} / \mathrm{PU}) /(\mathrm{FR} / \mathrm{FU})$ & $1 / \pi$ & $\cdot / \mu$ & (RP/RR)/(UP/UR) & $1 / \cdot$ & $\cdot / \cdot$ & $(\mathrm{FF} / \mathrm{FU}) /(\mathrm{UF} / \mathrm{UU})$ & $\cdot / 9$ & $\cdot / r$ \\
\hline TY & $(\mathrm{RP} / \mathrm{RU}) /(\mathrm{FP} / \mathrm{FU})$ & $1 / 1$ & $\cdot / r$ & (PF/PU)/(FF/FU) & $1 / \cdot$ & $\cdot / \cdot$ & (PP/PU)/(UP/UU) & $\cdot 19$ & $\cdot / r$ \\
\hline$T \Delta$ & $(\mathrm{RF} / \mathrm{RU}) /(\mathrm{UF} / \mathrm{UU})$ & $1 / 1$ & $\cdot / \pi$ & (FP/FR)/(UP/UR) & $\cdot 19$ & $\cdot / 1$ & (PR/PU)/(UR/UU) & $\cdot 1 \Lambda$ & $\cdot / 4$ \\
\hline צ & $(\mathrm{FP} / \mathrm{FF}) /(\mathrm{UP} / \mathrm{UF})$ & $1 / \cdot$ & $\cdot 11$ & $(\mathrm{PR} / \mathrm{PF}) /(\mathrm{RR} / \mathrm{RF})$ & $\cdot 19$ & $\cdot / 1$ & (RP/RF)/(UP/UF) & $\cdot 1 \Lambda$ & $\cdot 19$ \\
\hline
\end{tabular}


ادامه جدول ه: عناصر تشكيلدهنده فاصله آلثام بين سرشمارىهاى مختلف ي

\begin{tabular}{|c|c|c|c|c|c|c|c|c|}
\hline \multicolumn{3}{|c|}{ P:Irq+,Q:IrVD } & \multicolumn{3}{|c|}{ 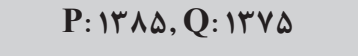 } & \multicolumn{3}{|c|}{$P:\|r q \cdot, Q:\| r \wedge \Delta$} \\
\hline 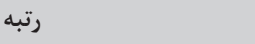 & نسبت & 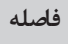 & & نسبت & 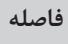 & & 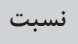 & 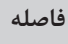 \\
\hline rV (FR/FU)/(UR/UU) & $1 / \cdot$ & $\cdot 11$ & $(\mathrm{RP} / \mathrm{RF}) /(\mathrm{UP} / \mathrm{UF})$ & $\cdot 19$ & $\cdot / 4$ & $(\mathrm{FP} / \mathrm{FF}) /(\mathrm{UP} / \mathrm{UF})$ & $\cdot / \Lambda$ & $\cdot 19$ \\
\hline 「^ (RF/RU)/(FF/FU) & $\cdot / \Lambda$ & $\cdot / 4$ & $(\mathrm{RR} / \mathrm{RF}) /(\mathrm{UR} / \mathrm{UF})$ & .19 & $\cdot / 4$ & $(\mathrm{RR} / \mathrm{RF}) /(\mathrm{UR} / \mathrm{UF})$ & $\cdot / V$ & $\cdot 19$ \\
\hline ५ $(\mathrm{RR} / \mathrm{RF}) /(\mathrm{FR} / \mathrm{FF})$ & $\cdot / \Lambda$ & $\cdot / \mathbb{F}$ & $(\mathrm{RF} / \mathrm{RU}) /(\mathrm{FF} / \mathrm{FU})$ & .19 & $\cdot / \mu$ & (RP/RU)/(UP/UU) & $\cdot / V$ & $\cdot / \mathrm{V}$ \\
\hline r. (PF/PU)/(UF/UU) & $\cdot 11$ & $\cdot / 4$ & $(\mathrm{RP} / \mathrm{RF}) /(\mathrm{FP} / \mathrm{FF})$ & $\cdot 1 \Lambda$ & 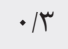 & $(\mathrm{RR} / \mathrm{RU}) /(\mathrm{UR} / \mathrm{UU})$ & $\cdot / V$ & $\cdot / V$ \\
\hline I (FR/FF)/(UR/UF) & $\cdot 11$ & $\cdot 10$ & $(\mathrm{PR} / \mathrm{PF}) /(\mathrm{UR} / \mathrm{UF})$ & $\cdot 11$ & $\cdot / 4$ & $(\mathrm{FR} / \mathrm{FF}) /(\mathrm{UR} / \mathrm{UF})$ & $\cdot / \mathrm{V}$ & $\cdot / 1$ \\
\hline r (PF/PU)/(RF/RU) & $\cdot / V$ & $\cdot 19$ & $(\mathrm{RR} / \mathrm{RF}) /(\mathrm{FR} / \mathrm{FF})$ & $\cdot 11$ & $\cdot 10$ & (FP/FU)/(UP/UU) & $\cdot / V$ & $\cdot / \Lambda$ \\
\hline سץ (RR/RU)/(UR/UU) & $\cdot / V$ & $\cdot 11$ & $(\mathrm{PR} / \mathrm{PF}) /(\mathrm{FR} / \mathrm{FF})$ & $\cdot / V$ & $\cdot 19$ & $(\mathrm{FR} / \mathrm{FU}) /(\mathrm{UR} / \mathrm{UU})$ & $\cdot 19$ & $1 / \cdot$ \\
\hline rF (RR/RU)/(FR/FU) & $\cdot / V$ & $\cdot 11$ & (RP/RU)/(FP/FU) & $\cdot / V$ & $\cdot 19$ & $(\mathrm{PF} / \mathrm{PU}) /(\mathrm{FF} / \mathrm{FU})$ & $\cdot / 4$ & $\mathrm{r} / \cdot$ \\
\hline$r^{\omega}(\mathrm{RR} / \mathrm{RF}) /(\mathrm{UR} / \mathrm{UF})$ & $\cdot 19$ & $\cdot 19$ & $(\mathrm{PR} / \mathrm{PU}) /(\mathrm{FR} / \mathrm{FU})$ & $\cdot / V$ & $\cdot 19$ & (PF/PU)/(RF/RU) & $\cdot / 4$ & 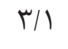 \\
\hline r (PF/PU)/(FF/FU) & $\cdot 19$ & $1 / \cdot$ & $(\mathrm{RR} / \mathrm{RU}) /(\mathrm{FR} / \mathrm{FU})$ & $\cdot / \mathrm{V}$ & $\cdot / 1$ & (PF/PU)/(UF/UU) & $\cdot / 4$ & $r / r$ \\
\hline
\end{tabular}

توضيح: در اين جدول P نشانخر طبقه شغلى (بخش عمومى)، R نشانخر "بخشخصوصى)، F نشانخر ( كشاورز)، و U نشانخر "(غيرماهر (") هستند.

جدول 9: عناصر تشكيلدهنده فاصله آثام در سرشمارىهاى مختلف

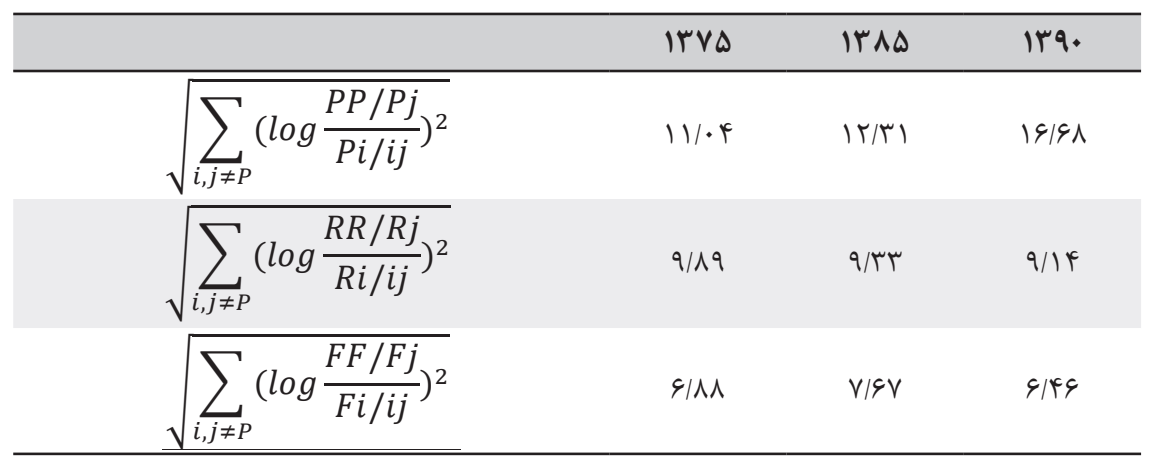

توضيح: در اين جدول P نشانغر طبقه شغلى (بخشعمومى)، R نشانخر (بخش خصوصى)، F نشانگر (اكشاورز)، و U نشانخر ("غيرماهر ") هستند. 


\section{بحث و نتيجه كيرى}

اين :زوهش يك شاخص سازحار را در طول زمان از تحرك شغلى بيننسلى در ايران ارائه مى كند

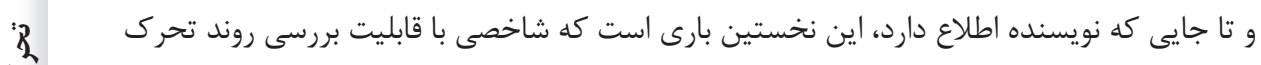

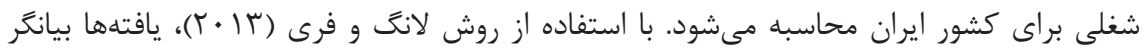

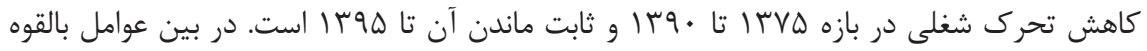

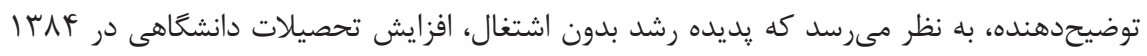

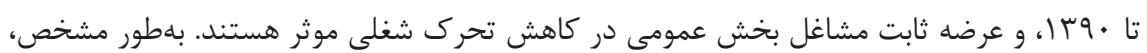
يافتهها نشان مىدهند كه بخش اصلى كاهش تحرك شغلى در اين دوره به دليل سخت تر شدن دستيابى به مشاغل بخش عمومى براى فرزندانى است كه يدرشان در اين بخش شاغل نيستند.

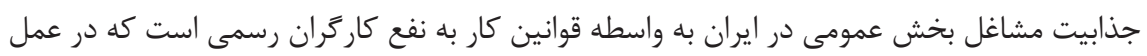

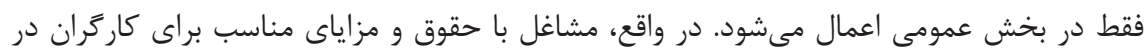
بخش خصوصى كمياب است و وجود شكاف دستمزدى بين بخش عمومى و بخش خصوصى موجب

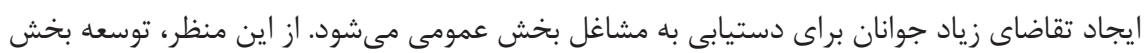

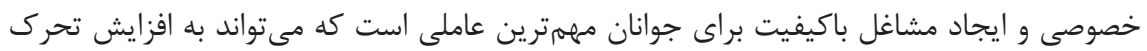

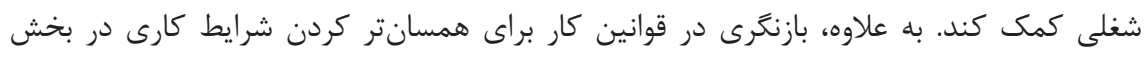

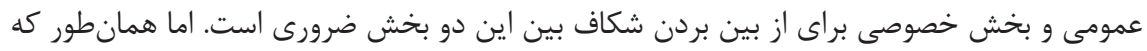

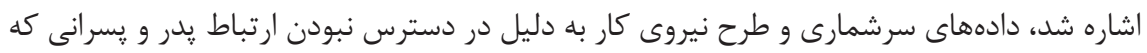

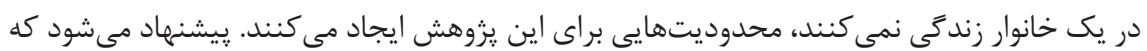

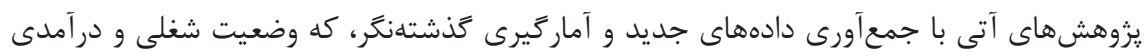

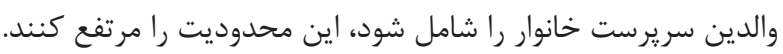

كشاورز حداد، غلامرضا، و علويان قوانينى، آرش (I9 (1)). شكاف جنسيتى دستمزد در مناطق شهرى ايران.

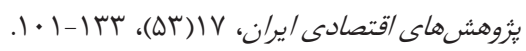




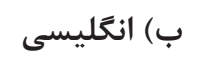

Altham, P. M. (1970). The Measurement of Association of Rows and Columns for an R $\times \mathrm{S}$ Contingency Table. Journal of the Royal Statistical Society: Series B (Methodological), 32(1), 63-73.

Altham, P. M., \& Ferrie, J. P. (2007). Comparing Contingency Tables Tools for Analyzing Data from Two Groups Cross-Classified by Two Characteristics. Historical Methods: A Journal of Quantitative and Interdisciplinary History, 40(1), 3-16.

Black, S., \& Devereux, P. (2011). Recent Developments in Intergenerational Mobility, Handbook of Labor Economics, (4, 1487-1541), Amsterdam, North-Holland.

Blau, P. M., \& Duncan, O. D. (1967). The American Occupational Structure. John Wiley \& Sons Inc.

Corak, M. (2013). Income Inequality, Equality of Opportunity, and Intergenerational Mobility. Journal of Economic Perspectives, 27(3), 79-102.

Emran, M. S., \& Shilpi, F. (2011). Intergenerational Occupational Mobility in Rural Economy Evidence from Nepal and Vietnam. Journal of Human Resources, 46(2), 427-458.

Emran, S., \& Sun, Y. (2015). Magical Transition? Intergenerational Educational and Occupational Mobility in Rural China: 1988-2002: The World Bank.

Guest, A. M., Landale, N. S., \& McCann, J. C. (1989). Intergenerational Occupational Mobility in the Late 19th Century United States. Social Forces, 68(2), 351-378.

Hnatkovska, V., Lahiri, A., \& Paul, S. B. (2013). Breaking the Caste Barrier Intergenerational Mobility in India. Journal of Human Resources, 48(2), 435-473.

Jäntti, M., \& Jenkins, S. P. (2015). Income Mobility. Handbook of Income Distribution (2, 807-935): Elsevier.

Long, J., \& Ferrie, J. (2013). Intergenerational Occupational Mobility in Great Britain and the United States since 1850. American Economic Review, 103(4), 1109-1137.

Modalsli, J. (2017). Intergenerational Mobility in Norway, 1865-2011. The Scandinavian Journal of Economics, 119(1), 34-71.

Reddy, A. B. (2015). Changes in Intergenerational Occupational Mobility in India: Evidence from National Sample Surveys, 1983-2012. World Development, 76(1), 329-343.

Ruiz, A. C. (2018). Intergenerational Occupational Dynamics Before and During the Recent Crisis in Spain. Empirica, 45(2), 367-393.

Solon, G. (1999). Intergenerational Mobility in the Labor Market Handbook of Labor Economics (3, 1761-1800): Elsevier.

Xie, Y., \& Killewald, A. (2013). Intergenerational Occupational Mobility in Great Britain and the United States since 1850: Comment. Shorter Papers, American Economic Review, 103(5), 2003-2020. 